\title{
Therapeutic Strategies Under Development Targeting Inflammatory Mechanisms in Amyotrophic Lateral Sclerosis
}

\author{
Sebastiano Giuseppe Crisafulli ${ }^{1} \&$ Simona Brajkovic ${ }^{1} \&$ Maria Sara Cipolat Mis ${ }^{1} \&$ \\ Valeria Parente ${ }^{1} \&$ Stefania Corti ${ }^{1}$
}

\begin{abstract}
Amyotrophic lateral sclerosis (ALS) is a neurological disease characterized by the progressive loss of cortical, bulbar, and spinal motor neurons (MNs). The cardinal manifestation of ALS is a progressive paralysis which leads to death within a time span of 3 to 5 years after disease onset. Despite similar final output of neuronal death, the underlying pathogenic causes are various and no common cause of neuronal damage has been identified to date. Inflammation-mediated neuronal injury is increasingly recognized as a major factor that promotes disease progression and amplifies the MN death-inducing processes. The neuroimmune activation is not only a physiological reaction to cell-autonomous death but is an active component of nonautonomous cell death. Such injury-perpetuating phenomenon is now proved to be a common mechanism in many human disorders characterized by progressive neurodegeneration. Therefore, it represents an interesting therapeutic target. To date, no single cell population has been proved to play a major role. The existing evidence points to a complex cross talk between resident immune cells and nonresident cells, like monocytes and $\mathrm{T}$ lymphocytes, and to a dysregulation in cytokine profile and in phenotype commitment. After a summary of the most important mechanisms involved in the inflammatory reaction in ALS, this review will focus on novel therapeutic tools that rely on tackling inflammation to improve motor function and survival. Herein, completed, ongoing, or planned clinical trials, which aim to modify the rapidly fatal course of this disease, are discussed. Anti-inflammatory compounds that are
\end{abstract}

$*$ Stefania Corti

stefania.corti@unimi.it

${ }^{1}$ Dino Ferrari Centre, Neuroscience Section, Department of Pathophysiology and Transplantation (DEPT), Neurology Unit, IRCCS Foundation Ca' Granda Ospedale Maggiore Policlinico, University of Milan, Via Francesco Sforza 35, 20122 Milan, Italy currently undergoing preclinical study and novel suitable molecular targets are also mentioned.

Keywords ALS · Inflammation · Microglia · Astrocytes · Anti-inflammatory drugs $\cdot$ ALS progression .

Neurodegeneration $\cdot$ Motor neurons

\begin{tabular}{|c|c|}
\hline \multicolumn{2}{|c|}{ Abbreviations } \\
\hline ALS & Amyotrophic lateral sclerosis \\
\hline A-SMase & Acid sphingomyelinase $\mathrm{ABC}$ \\
\hline & ATP-binding cassette \\
\hline ALSFRS-R & ALS function rating scale revised \\
\hline AMPA & $\begin{array}{l}\text { a-Amino-3-hydroxy-5-methyl-4-isoxazole } \\
\text { propionic acid }\end{array}$ \\
\hline AP1 & Activator protein 1 \\
\hline APP & Amyloid precursor protein \\
\hline Arg1 & Arginase 1 \\
\hline ATP & Adenosine triphosphate \\
\hline AUC & Area undercurve \\
\hline BDNF & Brain-derived neurotrophic factor \\
\hline KIT & Receptor tyrosine-kinase \\
\hline $\mathrm{C}(\max )$ & Maximum serum concentration \\
\hline $\mathrm{C} / \mathrm{EBP}$ & CCAAT-enhancer-binding protein \\
\hline C9ORF72 & Chromosome 9 open reading frame 72 \\
\hline CAFS & $\begin{array}{l}\text { Combined assessment of function and } \\
\text { survival }\end{array}$ \\
\hline CB2 & Cannabinoid receptor 2 \\
\hline CCAAT & $\begin{array}{l}\text { Cytidine-cytidine-adenosine-adenosine- } \\
\text { thymidine }\end{array}$ \\
\hline CD & Cluster of differentiation \\
\hline Chi313 & Chitinase-3-like-3 \\
\hline CNS & Central nervous system \\
\hline $\mathrm{COX}$ & Cyclooxygenase \\
\hline CRP & C-reactive protein \\
\hline
\end{tabular}




\begin{tabular}{|c|c|c|c|}
\hline CSF1 & Colony-stimulating factor 1 & $\mathrm{MN}$ & Motor neuron \\
\hline CSF1R & Colony-stimulating factor 1 receptor & MnSOD & Manganese-dependent superoxide dismutase \\
\hline CysGly & Cysteinylglycine & MRI & Magnetic resonance imaging \\
\hline EAAT/ & Excitatory amino acid transporter/glutamate & mRNA & Messenger RNA \\
\hline GLAST & aspartate transporter & MS & Multiple sclerosis \\
\hline EAAT/GLT1 & Excitatory amino acid transporter/glutamate & mSOD1 & Mutant SOD1 \\
\hline & transporter 1 & MyD88 & Myeloid differentiation primary response \\
\hline EDSS & Expanded Disability Status Scale & & gene 88 \\
\hline EMA & European Medical Agency & N-SMase & Neutral sphingomyelinase \\
\hline ER & Endoplasmatic reticulum & NCAM & Neural cell adhesion molecule \\
\hline ERK & Extracellular signal-regulated kinases & Nec-1 & Necrostatin-1 \\
\hline FACS & Fluorescence-activated cell sorting & $\mathrm{NF}-\mathrm{kB}$ & Nuclear factor kappa-light chain-enhancer of \\
\hline FADD & Fas-associated protein with death domain & & activated B cells \\
\hline fALS & Familial amyotrophic lateral sclerosis & NFAT & Nuclear factor of activated T cells \\
\hline FAS & Fas cell surface death receptor & NIV & Noninvasive ventilation \\
\hline FasL & Fas ligand & NMDA & N-methyl-D-aspartate \\
\hline FDA & Food and Drug Administration & NO & Nitric oxide \\
\hline FEV1 & Forced expiratory volume in the 1 st second & NOD & Nucleotide oligomerization domain \\
\hline FGF & Fibroblast growth factor & NTG & Normal tension glaucoma \\
\hline FIZZ1 & Found in inflammatory zone 1 & OPTN & Optineurin \\
\hline FoxP3 & Forkhead box P3 & PDGFR & Platelet-derived growth factor receptor \\
\hline FTD & Frontotemporal dementia & PET & Positron emission tomography \\
\hline FUS & Fused in sarcoma & PG & Prostaglandin \\
\hline FVC & Forced vital capacity & PI3K & Phosphatidylinositol 3-kinase \\
\hline GDNF & Glial cell-derived neurotrophic factor & PKA & Protein kinase A \\
\hline GIST & Gastrointestinal stromal tumor & PML & Progressive multifocal encephalitis \\
\hline HHD & Hand-held dynamometry & PPAR & Peroxisome proliferator-activated receptor \\
\hline HLA & Human leukocyte antigens & RAGE & Receptors for advanced glycation end \\
\hline HMGB1 & High mobility group box 1 & & products \\
\hline HSE & Herpes simplex encephalitis & RIG & Retinoic acid-inducible gene \\
\hline HSP & Heat shock protein & RIP & Receptor-interacting protein \\
\hline IFN & Interferon & RIPK & Receptor-interacting serine/threonine kinase \\
\hline IGF & Insulin-like growth factor & ROS & Reactive oxygen species \\
\hline $\mathrm{IkB}$ & Inhibitor of $\mathrm{kB}$ & RUNX & Runt-related transcription factor \\
\hline IL & Interleukin & S1P & Sphingosine-1-phosphate \\
\hline iNOS & Inducible nitric oxide synthase & sALS & Sporadic amyotrophic lateral sclerosis \\
\hline iPSC & Induced pluripotent stem cells & SCID & Severe combined immunodeficiency \\
\hline IRAK & Interleukin-1 receptor-associated kinase & shRNA & Short hairpin RNA \\
\hline IRF & Interferon regulatory factor & SOCS & Suppressor of cytokine signaling \\
\hline JNK & c-Jun N-terminal kinase & SOD1 & Superoxide dismutase 1 \\
\hline KIR3DL2 & Killer cell immunoglobulin-like receptor 3DL2 & STAT & Signal transducer and activator of \\
\hline LMN & Lower motor neuron & & transcription \\
\hline LPS & Lipopolysaccharide & SVC & Slow vital capacity \\
\hline LTP & Long-term potentiation & TACE & TNF-alpha converting enzyme \\
\hline Mal & MyD88-adapter-like & TANK & TRAF family member-associated NF-kB \\
\hline MAPK & Mitogen-activated protein kinase & & activator \\
\hline $\mathrm{MCP}$ & Monocyte chemoattractant protein & TARDBP & Transactive response DNA-binding protein \\
\hline mGluR & Metabotropic glutamate receptor & TBK1 & TANK binding kinase 1 \\
\hline MHC & Major histocompatibility complex & TDP-43 & Transactive response DNA-binding protein \\
\hline MIF & Migration inhibitory factor & & $43 \mathrm{kDa}$ \\
\hline MIP & Maximum inspiratory pressure & TGF & Transforming growth factor \\
\hline MLKL & Mixed lineage kinase domain-like protein & Th & $\mathrm{T}$ helper \\
\hline MMT & Manual muscle testing & TIR & Toll/IL-1 receptor \\
\hline
\end{tabular}




$\begin{array}{ll}\text { TLR } & \text { Toll-like receptor } \\ \text { TNF } & \text { Tumor necrosisfactor } \\ \text { TNFR } & \text { Tumor necrosis factor receptor } \\ \text { TRADD } & \text { TNFR1-associated death domain } \\ \text { TRAF2 } & \text { TNFreceptor-associated factor } 2 \\ \text { TRAIL } & \text { TNF-related apoptosis-inducing ligand } \\ \text { Treg } & \text { Regulatory T cells } \\ \text { TSPO } & \text { Translocator protein } 18 \mathrm{kDa} \\ \text { VEGF } & \text { Vascular endothelialgrowth factor } \\ \text { VZV } & \text { Varicella zostervirus } \\ \text { WT } & \text { Wild type } \\ {[11 C] P B R 28} & {[11 \mathrm{C}] \text { peripheral benzodiazepine receptor 28 }}\end{array}$

\section{Introduction}

Amyotrophic lateral sclerosis (ALS) is a degenerative neurologic disease with an adult-age onset. ALS is marked by the selective death of spinal, bulbar, and cortical motor neurons (MNs), ultimately causing progressive paralysis and precocious death usually occurring 3 to 5 years after the diagnosis[1].

In the majority of cases ( $90 \%)$, no familial history of ALS is recognized, thus being classified as sporadic forms of ALS (sALS), while only $10 \%$ of ALS cases are familial (fALS). More than 10 different mutated genes have been associated with fALS [2] cases. The expansion in the hexanucleotide repeat (GGGGCC) ${ }_{n}$ in the chromosome 9 open reading frame 72 (C9ORF72) gene (accounting for about $40 \%$ of fALS in Western countries) and mutations in the superoxide dismutase 1 (SOD1), fused in sarcoma

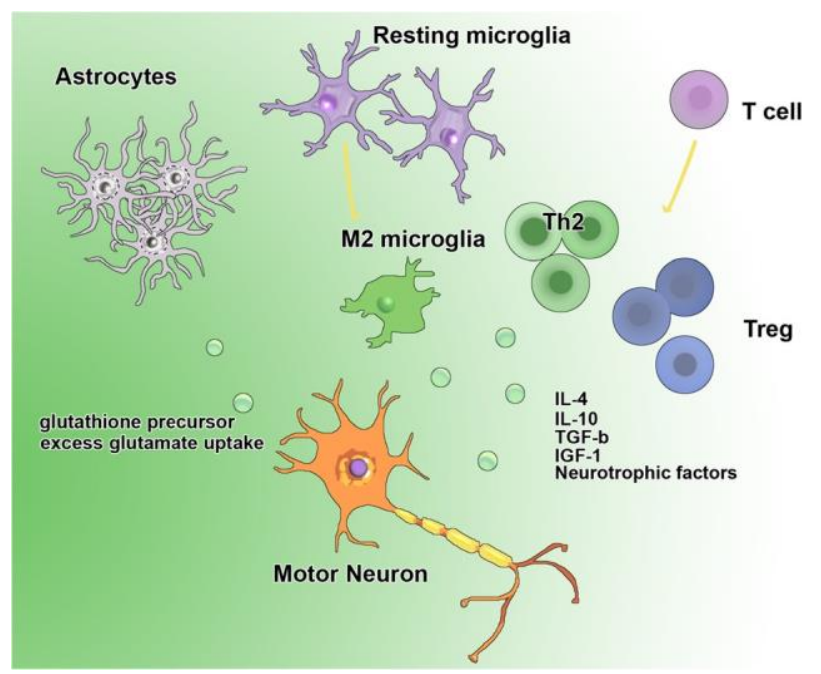

Fig. 1 The ambivalent role of inflammation on motor neuron survival. Left: Resting state astrocytes, M2 microglia, Th2, and Treg lymphocytes are predominantly present at an early stage of disease and support neuron function and viability by removing glutamate excess from the extracellular space and releasing anti-inflammatory and neurotrophic factors (IL-4, IL-10, TGF- $\beta$, IGF-1, BDNF, GDNF). Right: Danger signals and misfolded or mutated proteins (like mSOD1 and TDP-43)
$(F U S)$ and transactive response DNA binding protein $43 \mathrm{kDa}(T D P-43$ or TARDBP) genes (identified in about $20,1-5$, and $1-5 \%$ of fALS patients, respectively) are recognized as the underlying cause of the majority of fALS cases.

Despite our current knowledge, the underlying pathogenic mechanism remains unclear, especially for sALS. Besides riluzole, which can extend the median survival of ALS patients only by 3 months, no other approved therapy exists for ALS. It is urgent to identify new potential therapeutic targets in order to develop treatments that can have a clinically meaningful impact.

The inflammatory reaction in the central nervous system (CNS) is emerging as a potential pathogenic and precipitating factor in a broad spectrum of degenerative diseases [3]. Neuroinflammation has been demonstrated in areas of neuronal loss in both animal and human tissues, even during the presymptomatic phase of the disease, but its role is far to be completely elucidated [4]. There is no definitive evidence whether inflammation is a major cause of cell death or if it represents a reaction to local damage signals derived from dying MNs, mutant proteins, or self-antigens. However, the emerging fact regarding neuroinflammation is its ambivalent action on ALS onset and course, being neuroprotective and repair driving during an early phase and becoming cytotoxic in an advanced phase (Fig.1) [5]. Another interesting evidence of noncell-autonomous neuronal death is that neurons expressing mutant SOD1 (mSOD1) show no major pathological sign when supported by healthy macroglia and microglia, while MNs lacking SOD1 develop pathologic hallmarks of ALS when exposed to glial cells expressing mSOD1 [6].

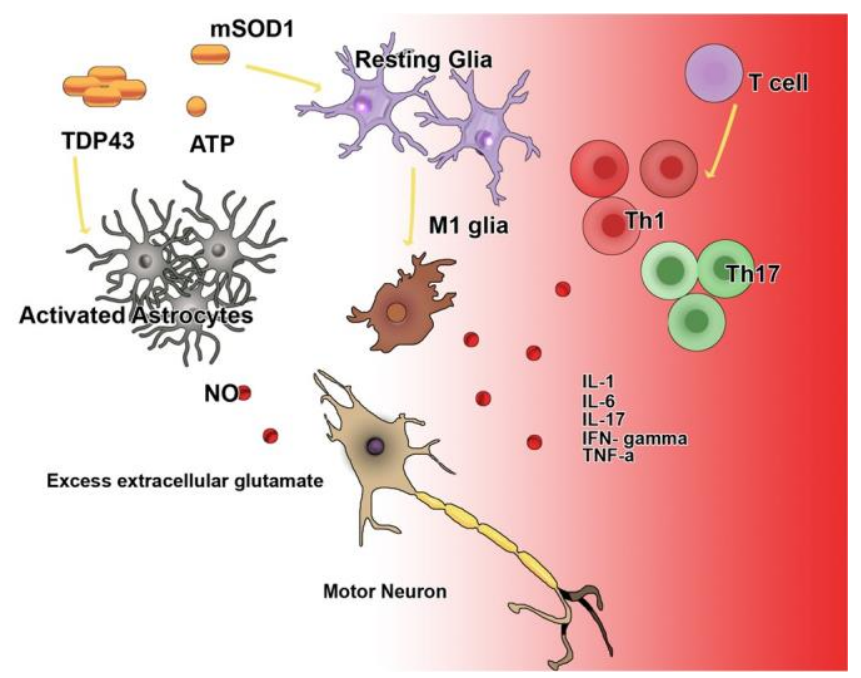

cause a switch of immune cells to a pro-inflammatory and neurotoxic state, which is predominant at a late stage of disease. Activated astrocytes, M1 microglia, and Th1 and Th17 lymphocytes secrete nitric oxide (NO) and pro-inflammatory factors (IL-1, IL-6, IFN- $\gamma$, TNF- $\alpha$ ) that induce neurotoxicity and death of motor neurons. The impairment of glutamate uptake by activated astrocytes increases excitotoxicity and apoptosis of motor neurons 
The major inflammatory pathways studied include microglia and astrocyte activation, recruitment of peripheral monocytes, the role of lymphocytes, and their ability to regulate the type and strength of immune response [7].

Given this evidence, several compounds targeting neuroinflammation such as celecoxib [8], ceftriaxone, thalidomide, and minocycline have been tested in preclinical stage and have been shown to exert positive effects on ALS transgenic mice [9-11] in the last years. However, none of them has been proved to be effective when transferred to human clinical trials. In a similar way, counteracting the negative effect of reactive oxygen species (ROS) exerted positive effects on ALS animal models but not on ALS patients [12]. Indeed, several well-known immunosuppressive drugs such as azathioprine, corticosteroids, cyclophosphamide, and calcineurin inhibitors like cyclosporine, which have a well-established efficacy on many immunological disorders and are routinely used, had not demonstrated any therapeutic efficacy in ALS $[13,14]$. Also, some immunomodulatory drugs used for multiple sclerosis (MS), like glatiramer acetate, have been disappointing in a clinical setting [15].

The reasons of this failure are largely unknown. Such failure can be reasonably due to the fact that these drugs are generally administered when the disease has already progressed to an advanced phase. During this phase, inflammation could no longer represent an appropriate target or it is also likely that inflammatory pathways could contribute in a more complex way to ALS than to other neurological diseases with a clear inflammatory pathogenesis.

In this review, we propose a brief overview of the changes in innate and adaptive immunity and the evidence of their involvement in ALS. Then, we will discuss recent studies and ongoing or planned clinical trials that investigated the effects of anti-inflammatory and immune-modulating drugs on disease onset and progression. The different compounds are classified based on their main putative molecular/cellular targets.

\section{Microglia and ALS}

Several studies have demonstrated that glial cells, activated lymphocytes, and production of pro-inflammatory and neurotoxic agents have a role in the degeneration of MNs [16-18]. Increased activation of glial cells in ALS patients has been shown upon postmortem analysis [19] and with in vivo imaging techniques [20-22]. A good marker of enhanced glial activation is the translocator protein (TSPO), which is highly expressed in activated microglia [23]. Positron emission tomography (PET) imaging with the TSPO-binding radiotracer [11C] peripheral benzodiazepine receptor 28 ([11C]PBR28) has showed that the uptake of this compound was increased in the corticospinal tract and in the motor cortex of ALS patients compared to controls [24]. Also, this technique has showed a strong link between the anatomical localization of active microglia and the clinical manifestation of the disease.

Microglial cells express different classes of receptors typically associated with the innate immunity. The most important and known of them are Toll-like receptors (TLRs), nucleotide oligomerization domain receptors (NOD), receptors for advanced glycation end products (RAGE), and retinoic acidinducible gene (RIG) [25]. The activation of these receptors can be triggered by a variety of danger and damage signals,

like the accumulation and aggregation of abnormal or misfolded proteins and the release of cellular components from damaged or dying cells. These factors are wellrecognized pathogenic factors in different forms of ALS as previously described.

When activated, glial cells can acquire a M1 proinflammatory phenotype (classically activated microglia) or a M2 anti-inflammatory phenotype (alternatively activated microglia) [26]. M2-type glia has a positive effect on MN function and survival [27] and is mainly present at an early stage of disease, which is often a slow progression phase [28]. As the disease progresses, microglia strongly tend to switch to a M1 phenotype, enhancing the production of ROS and inflammation-inducing cytokines such as tumor necrosis factor- $\alpha$ (TNF- $\alpha$ ), interleukin-1 (IL-1), and IL- 6 and reducing the production of neurotrophic factors like insulin-like growth factor-1 (IGF-1) and IL-4 [29]. In fact, IGF-1 and, more recently, IGF2 [30] have been shown to prolong MN survival and ameliorate motor function in ALS mice [31]. Recently, RNAseq analysis has shown that TNF- $\alpha$ represents one of the most significant molecular alteration in the human ALS spinal cord [32].

TNF- $\alpha$ is first synthetized as a transmembrane protein and then cleaved by the TNF- $\alpha$ converting enzyme (TACE) to release its soluble form. Both the transmembrane and the soluble forms are active and able to bind to specific neuronal receptors, which are the effectors of the TNF- $\alpha$-induced toxicity [33]. TNF- $\alpha$ has two different membrane receptors: tumor necrosis factor receptor 1 (TNFR1), which possesses a death domain in its cytoplasmatic portion, and TNFR2 [34]. The soluble form of TNF- $\alpha$ activates TNFR1, which in response recruits the adaptor protein TNFR1-associated death domain (TRADD). The latter in turn activates other adaptor proteins downstream, like receptor-interacting protein (RIP), TNF receptor-associated factor 2 (TRAF2), and Fasassociated protein with death domain (FADD), that ultimately lead to the activation of caspase 8 and caspase 10 and to apoptosis. Furthermore, TNFR1 is also responsible for the activation of other intracellular signal pathways related to cell survival and inflammatory response such as extracellular signal-regulated kinase(ERK), p38 mitogen-activated protein kinase (p38 MAPK), c-Jun N-terminal kinase (JNK), the acidic and neutral sphingomyelinase (A-SMase and N-SMase), and nuclear factor kappa-light chain-enhancer of activated B 
cells (NF-kB) [35]. TNFR2 has been shown to induce apoptosis and activate NF-kB, ERK, p38 MAPK, and JNK through adaptor proteins TRAF2 and FADD [36]. The role of TNFR2 is still not completely understood, as other studies have showed that it could also have a neuroprotective effect [34]. Indeed, anti-TNF drugs are associated with neurological adverse events and negative effects on myelin [37]. The detrimental effect of TNF in neurodegeneration is amplified by its autocrine and paracrine action. The production of TNF- $\alpha$ is increased by TNF- $\alpha$ itself through binding to the TNFR1 [38] and to the group 2 metabotropic glutamate receptor (mGluR2) expressed by microglial cells. TNF signaling also increases the release of Fas ligand (FasL) [39] and glutamate from microglial cells [40]. Furthermore, glutamate toxicity is amplified by the impairment in the glutamate homeostasis system induced by TNF- $\alpha$ [41]. The downregulation of the excitatory amino acid transporter/glutamate aspartate transporter (EAAT1/GLAST) and excitatory amino acid transporter/ glutamate transporter 1 (EAAT2/GLT1) on astrocytes, triggered by the activation of TNFR1 and secondarily of NF-kB [42], results in decreased glutamate uptake from the extracellular space $[43,44]$. The reduced expression of these transporters has been demonstrated to occur both in rat models [45] and in ALS patients [46]. At the same time, it has been described that neurons exposed to TNF- $\alpha$ increase the expression of a-amino-3-hydroxy-5-methyl-4-isoxazole propionic acid(AMPA) [47] and N-methyl-D-aspartate(NMDA) receptors [48], which cause increased $\mathrm{Ca}^{+2}$ influx and excitotoxicity [49].

Microglial activation and polarization are highly dependent on the surrounding environment and signals from surrounding cells. Lipopolysaccharide (LPS) and interferon- $Y$ (IFN- $\gamma)$ promote a classical activation pathway (M1), whereas IL-4 and IL-13 induce the alternative activation pathway (M2) [50]. Notably, it has been speculated that IL-13 could also be able to modulate inflammation in the CNS by decreasing the survival of activated microglia [51]. The term M2 microglial also includes another microglial state called Bacquired deactivation, $\wedge$ which is induced by IL-10 and transforming growth factor- $\beta$ (TGF- $\beta$ ) and the uptake of apoptotic bodies [52]. As well as alternatively activated ones, glial cells that undergo acquired deactivation appear to foster repair and neuron survival [53]. M2-related cytokines are not produced exclusively by Th2 lymphocytes but are also produced by microglia, astrocytes, and neurons themselves in the CNS and show a paracrine and autocrine activity $[51,54,55]$.

The molecules Found in inflammatory zone 1 (FIZZ1), mannose receptor (CD206), chitinase-3-like-3 (Chi313), and arginase 1 (Arg1) are considered typical M2 markers. The most studied and interesting of them is Arg1. Along with inducible nitric oxide synthase (iNOS), Arg1 is a key enzyme in the metabolism of arginine in the nervous system, using this amino acid as its only substrate. iNOS uses arginine to produce nitric oxide (NO) and citrulline, while arginine metabolized by Arg1 gives urea and ornithine. Urea and ornithine are converted to hydroxyproline, proline, and polyamines [56]. These products not only contribute to cellular processes such as growth and differentiation [57], but proline and hydroxyproline are key components of the extracellular matrix and collagen $[58,59]$. It has been described that Arg 1 could reasonably have a neuroprotective effect that is not directly related to its products. Indeed, by consuming arginine, Arg1 could compete with iNOS for the use of available arginine, thus limiting the amount of this amino acid available for NO synthesis $[60,61]$.

As microglial cells represent the primary immune cells in the CNS, microglial activation correlates with many stimuli and danger signals. mSOD1 is responsible for microglial activation through cluster of differentiation 14 (CD14), TLR2 and TLR4 [62], and adenosine triphosphate (ATP) released from damaged or dying cells.

The upregulation of TLRs in ALS patients [63], including TLR4 and its ligand high-mobility group box 1 (HMGB1), and the protective action of TLR4 antagonism have been studied in murine models of MN degeneration [64] and support the possible pathogenic role of TLR4. A preclinical study using mSOD1 transgenic mice has characterized the expression of both TLR4 and its ligand during determined stages of disease. The study has demonstrated that the deletion of TLR4 has a beneficial effect on disease progression. The levels of both HMGB1 and TLR4, along with the respective messenger RNA (mRNAs), were shown to be higher in mSOD1 mice than in wild-type (WT) controls. Also, they were shown to be especially upregulated in microglial and astrocytic cells. In this perspective, the authors have generated a transgenic mouse lacking TLR4 which exhibited a prolonged disease course and a significant improvement of motor performance, confirming that TLR4 is a notable player in $\mathrm{MN}$ degeneration [65]. Given these results, the inhibition of TLRs, particularly TLR4, could hold promise as a pharmacological target. Recently, the beneficial effect of TLR4 antagonists in cellular models has been studied. Two synthetic glycol-lipoic molecules have been tested in LPS and mSOD1 animal models. One of the two molecules inhibits LPS-induced TLR4 activation, while the other one directly interacts with TLR4 and prevents its activation. Protective effects against LPS and cytokine toxicity have been demonstrated on MNs in spinal cord cultures. Positive results have also been shown in cocultures of MNs and glial cells derived from mSOD1 mice, reducing glia-mediated $\mathrm{MN}$ death. We advise that more experimental data are needed in order to demonstrate the efficacy of such therapies in vivo. 
Among the receptors crucial to innate immunity TLRs, TLR4 is expressed by the majority of both immune and nonimmune cells, including CNS-resident immune cells $[66,67]$. Activated TLR 4 can enhance the secretion of many cytokines and so promote the neuroinflammatory mechanisms that have been demonstrated to be involved in ALS. The Toll/IL-1 receptor (TIR) region is the protein domain responsible for signal transduction and is present in all TLRs. Upon activation of TLRs, this region binds adaptor proteins such as myeloid differentiation primary response gene 88 (MyD88) and MyD88adapter-like (Mal), which contain a TIR domain. Mal can form either homodimers or heterodimers with MyD88 and can activate NF-kB through the interaction with interleukin1 receptor-associated kinase 2 (IRAK2). Instead, MyD88 seems to activate NF-kB via IRAK1 [68]. The products of the classical NF-kB activation are NO and TNF- $\alpha$ and can be measured as indicators of NF-kB activation. As proved by in vitro co-cultures of MNs with WT or mSOD1 microglia, the products downstream of NF-kB activation released by mSOD1 microglia are toxic to MNs. Interestingly, NF-kB activation in WT microglia decreased MN survival by $50 \%$ in co-cultures. This has been confirmed by the fact that the inhibition of NF-kB, either by overexpression of inhibitor of $\mathrm{kB}$ (IkB) or transgenically, can rescue MNs [69]. The importance of NF-kB activation in microglia is further supported by the fact that TDP-43 and FUS have been proved to be coactivators of NF-kB [70, 71]. Indeed, the inhibition of NF$\mathrm{kB}$ in mice that express the mutant form of TDP-43 has resulted in an improvement of motor function and phenotype [70]. These studies seem to have recognized NF-kB as the common pathway activated by many pathogenic stimuli involved in ALS and as the crucial factor of microglia-mediated damage. Alongside the good therapeutic potential of NF-kB inhibitors, we think that this approach could require a good degree of specificity in targeting this nuclear factor just in microglia. In fact, the activity of NF-kB in neurons has been demonstrated to be important for many functions such as long-term potentiation (LTP) and, consequently, for memory, synaptic plasticity, and the ability to elaborate spatial information [72-74]. Many genes involved in neurite growth and migration [protein kinase A (PKA) [75], amyloid precursor protein (APP) [76], neural cell adhesion molecule (NCAM), $\beta 1$-integrin [77]], calcium homeostasis (calbindin [78, 79]), and neurotrophic signals [brain-derived neurotrophic factor (BDNF) [80]] are target genes of NF-kB. NF-kB has also been demonstrated to enhance the expression of manganesedependent SOD (MnSOD or SOD2) [81] both in neurons and nonneuronal cells and so could have a role in protecting neurons from apoptosis and from the damaging effects of ROS [82]. MnSOD is a mitochondrial protein and its function is to clear ROS, particularly superoxide, which is a toxic byproduct of mitochondria [83]. The neuroprotective effect of SOD2 has been shown in animal models of Alzheimer's disease [84] and in mice with traumatic brain damage [85]. Notably, the area of cortical damage has been shown to be larger in mice in which the TNFR gene is knocked-out as compared to WT [85]. In fact, abolishment of the signal downstream of the TNFR resulted in decreased activation of NF-kB and disrupted upregulation of MnSOD. The protective effect was also abolished in neurons in which NF-kB was inhibited by a $\mathrm{kB}$ decoy DNA [82].

\section{Astrocytes}

The major role of astrocyte is to nourish neurons and to sustain proper neuronal function. One of the ways by which astroglia exert its function is by regulating the extracellular glutamate concentration. In fact, glutamate clearance is impaired in ALS because of the lower levels of the molecule EAAT2, a glutamate transporter normally expressed by astrocytes, hence increasing extracellular glutamate [86]. This functional impairment is the rationale for the clinical use of riluzole, which is the only pharmacological therapy approved for ALS to date. Astrocytes also contribute to glutathione synthesis by secreting glutathione precursor cysteinylglycine (CysGly), thus enhancing neurons' defenses against oxidative injury [87]. This function has been shown to be compromised in astrocytes upon activation.

Astrocytes participate in the cellular response to damage and danger signals releasing inflammation-related molecules like NO, IL-6, and TNF- $\alpha$ and can induce the apoptosis of neurons through FasL [88] and TNF- $\alpha$ signaling [89] as described for microglia. TNF- $\alpha$ acts as previously described.

While activated microglial cells seem to be responsible for propagation and clinical progression of the disease after the onset, astrocytes could be directly involved in the disease onset. In fact, neural progenitor cells derived from induced pluripotent stem cells (iPSC) from ALS patients have been shown to differentiate into astrocytes once transplanted into the spinal cord of severe combined immunodeficiency (SCID) mice and induce a motor deficit [90]. Many other possible mechanisms through which astrocytes can trigger $\mathrm{MN}$ death have been proposed in the last years. Astrocytes have been shown to secrete factors that drastically reduce the expression of class I major histocompatibility complex (MHC I) on MNs [91]. The loss of MHC I expression has been demonstrated in MNs cultured with astrocytes expressing mSOD1, in MNs cultured with mSOD1 astrocyte conditioned medium, and in the mSOD1 mouse model. The same phenomenon has been described to occur in patients with fALS or sALS. In fact, spinal cord samples from these patients stained with antibodies against human leukocyte antigens (HLA) A, HLA-B, and HLA-C have showed a near complete loss of MHC I on MNs. The causative toxic factors have not been identified yet but are probably secreted only by astrocytes since mSOD1 microglia has not altered the expression of MHC I molecules on MNs in 
co-cultures. Classical inflammatory mediators, such as TNF- $\alpha$, IL-1, and IFN- $\gamma$ produced by activated astrocytes, have proved to have no effect on MHC I expression. Instead, up to $76 \%$ of cultured MNs lost the expression of MHC I after being treated with thapsigargin. This compound triggers the stress of the endoplasmic reticulum (ER) by inhibiting the ER calcium-ATPase. We speculate that the loss of MHC class I molecules could be a key pathogenic factor in the selective vulnerability of MNs to astrocyte toxicity. Indeed, overexpression of MHC class I subclasses, especially $\mathrm{H} 2 \mathrm{k}$, in mSOD1 mice through a viral vector has been demonstrated to fully rescue MNs from astrocyte-related toxicity, both in co-cultures and in vivo, and to increase survival as well motor function. The same results have been obtained by overexpressing HLA-F in human MNs which were cocultured with astrocytes derived from patients with fALS and sALS. MHC I molecules modulate astrocyte activation by binding to inhibitory receptors which have been shown to be expressed by astroglia in mSOD1 mice and in humans. Among many MHC I receptors, killer cell immunoglobulinlike receptor 3DL2 (KIR3DL2) has been found to be expressed only by astrocytes from ALS patients. The in vitro results have been confirmed by analysis of RNA expression in postmortem spinal cord specimens from individuals with ALS.

Furthermore, astrocytes have been shown to induce MN death by activating an alternative pathway of programmed cell death called necroptosis [92]. Necroptosis represents a form of programmed necrosis which is independent from the activation of caspases and involves the loss of the plasma membrane integrity. Two main effector proteins of necroptosis, receptorinteracting serine/threonine-protein kinase 1 (RIPK1) and mixed lineage kinase domain-like (MLKL), have been identified to date. In vitro inhibition of the necroptosis pathway, by the RIPK1 antagonist necrostatin-1 (Nec-1) or by direct silencing of RIPK1 via a short hairpin RNA (shRNA), has been reported to protect MNs from astrocyte-induced toxicity [93]. The inhibition of MLKL with necrosulfonamide has also been shown to rescue MNs from astroglia toxicity almost completely. Such results suggest that necroptosis could be required for MN degeneration induced by astroglial cells and thus could represent a new, interesting therapeutic target. However, we highlight that the toxic soluble factors released by astrocytes are yet to be identified with certainty. Although TNF- $\alpha$, FasL, and TRAIL can trigger necroptosis and are also known to be released by astrocytes and microglia upon activation, some studies have reported that none of these factors was identified in MSOD1 or sALS astrocyte-conditioned media.

Since astrocytes are now recognized to contribute more than previously thought to MN loss, an interesting approach would be to replace ALS astrocytes with wild-type or modified cells that can mitigate the toxic environment, modulate neuroinflammation, and foster the MN repair process [16].
Several studies have been conducted grafting different types of cells in the mSOD1 murine model: human neural precursor overexpressing vascular endothelial growth factor (VEGF), BDNF, IGF-1, or glial cell-derived neurotrophic factor (GDNF) [94]; human umbilical cord blood cells overexpressing VEGF and fibroblast growth factor 2 (FGF2) [95]; rat glial restricted neural precursors [96]; and rat adult mesenchymal stem cells [97]. All cell types have been shown to differentiate into astrocytes, retain growth factor secretion, and reduce neuroinflammation. The effect on motor function and survival has been reported to be variable from no effect $[94,97]$ to increased survival and improved motor function [96] or has not been reported in other studies [95]. Currently, there is no consensus on which cell type could provide the best safety and efficacy profile, nor on the route of administration. Several clinical trials are now ongoing to evaluate this approach.

\section{T Lymphocytes}

Although T lymphocytes probably do not exert a direct action in the pathogenic cause of this disorder, they are involved in a complex cross talk with the CNS-resident immune cells and can drive the activation and polarization of the surrounding glia and astrocytes. CD4+ T lymphocytes are recalled to the brain and the spinal cord early during the disease and rise in number as ALS progresses. CD4+ lymphocytes remain the predominant $\mathrm{T}$ cell subpopulation.

As with microglia, Tcells have been recognized to predominantly assume two phenotypes, one with anti-inflammatory and immune-modulating properties [ (T helper (Th) 2 and regulatory $\mathrm{T}$ cells(Treg)) [98] and the other one with proinflammatory and toxicity-prone characteristics (Th1 and Th17). Th1 and Th17 secrete predominately IL-1, IL-6, and IFN- $\gamma$, while Th 2 and Treg release TGF- $\beta$, IL-4, and IL-10. The neuroprotective action of T cells is supported by in vivo studies on mSOD1 transgenic mice lacking functional T cells, which showed a faster disease progression and a marked shortening in survival [99]. In many studies, mostly on mouse models, $\mathrm{T}$ cells have been proven to behave like glial cells. They have showed a preferred polarization toward Th2 and Treg early during the disease and a switch to Th1 and Th17 at a late, fast progression phase. This has been confirmed by the analysis of mRNA expression [28]. Given the similarity, not only in the type of behavior but also in the phase of the disease during which these phenotypic changes occur, it is likely that $\mathrm{T}$ lymphocytes and glial cells are interdependent and closely influence each other's properties. In fact, IL-4 produced by Treg cells can abolish the cytotoxic effect of microglia [100], and at the same time, M2 microglia can promote the acquisition of Th2 or Treg phenotype [101]. This phenomenon has been demonstrated to occur also in humans. In ALS patients, the blood count of Treg cells has been inversely associated with a faster disease progression. The same 
correlation has been observed with the levels of the transcription factor forkhead box P3 (FoxP3) in leucocytes [102]. Interestingly, the factors that are specific of Th1 and Th17, such as IL-6, IL-1, and INF- $\gamma$, can inhibit the phosphorylation of FoxP3, thus inhibiting the immune suppression mediated by Treg cells [103] and facilitating their switch to Th17 lymphocytes [104].

\section{Peripheral Immune System}

The role of peripheral monocytes/macrophages remains controversial. There is no clear evidence that they can infiltrate the spinal cord and contribute to MN death [105] unless there is a disruption in the blood-brain barrier [106]. However, their damaging action on peripheral axons has been well recognized [107]. The increased activation of circulating monocytes has been described in ALS patients [108].

It is clear though that the characteristics of the many cellular components of the immune system are not the result of the influence of a single cell type or a unique cytokine or factor but the consequence of the complex milieu of signals and factors. These factors seem to be worsening over time and are now being recognized as major players in MN degeneration. What seems to be the most likely scenario is that an early slowly progressing phase, during which immune cells drive the repair processes and support MN function and viability, is followed by a late fast progressing phase. During this late stage, the cell-autonomous neuronal injury could also be responsible for a progressive switch in glia, astrocyte, and T cell phenotype through the release of apoptotic bodies, misfolded proteins, and ATP. This ultimately results in the amplification of injury and neurotoxic environment [5].

In this perspective, reducing the inflammation and modulating the reaction of immune cells appear as a promising strategy to consistently influence the progression and prognosis of ALS.

\section{Experimental Drugs}

Drugs with different mechanisms of action and molecular targets have been or are currently studied in clinical trials. Even if inflammation is a complex process and the altered behavior of a cell type can greatly influence that of other cells, many drugs can be classified based on their primary cellular target. Masitinib, ibudilast, and NP001 are reported to act predominantly on microglia by modulating microglial activation, survival, and production of pro-inflammatory mediators. Instead, $\mathrm{T}$ lymphocytes are the primary target of fingolimod. Fingolimod causes T cells to be retained to secondary lymphoid organs, consequently hindering their migration to the CNS and peripheral nerves.
Since cytokines are crucial mediators of inflammation, drugs targeting pro-inflammatory cytokines could represent a valuable tool and have been tested in clinical trials. Such drugs include anakinra, an anti-IL-1 receptor monoclonal antibody, and tocilizumab, a monoclonal antibody directed against the IL-6 receptor.

Other anti-inflammatory drugs with a wider spectrum of cellular targets have also been studied. Given the lack of a precise cellular target, they were classified as other antiinflammatory drug in this work. These compounds include RNS60, pioglitazone, celecoxib, celastrol, AM-1241, and folic acid. The mechanism of action of the different drugs is described in the dedicated sections (Table 1, Fig. 2).

\section{Drugs Targeting Microglia and Macrophages}

\section{Masitinib (AB1010)}

A way to tackle inflammation is inhibiting the kinases involved in this process and in apoptosis. Masitinib, a molecule that can selectively inhibit the tyrosine-kinase mast/stem cell growth factor receptor (c-KIT) and a small number of other kinases [109], is a potential therapeutic drug and can be administered orally. Masitinib blocks microglia proliferation and activation and mast cell-mediated degranulation [110] and the release of cytotoxic factors that could worsen the injury to motor nerves. The inhibition of microglia is also mediated by the blockade of colony-stimulating factor 1 receptor (CSF1R) [111].

Compared to other molecules with inhibitory activity on tyrosine-kinases, masitinib is characterized by a relative selectivity for its target and requires half the concentration to exert its activity, thus suggesting that masitinib could have milder or less side effects. Indeed, genotoxicity or cardiotoxicity has not been reported [109]. Several clinical trials have been conducted on rheumatologic and neoplastic diseases such as gastrointestinal stromal tumors (GIST) [112, 113], in pancreatic ductal adenocarcinoma [114, 115], colorectal tumors (ClinicalTrials. gov Identifier: NCT02605044), and melanoma (ClinicalTrials.gov Identifier: NCT01280565). Furthermore, masitinib has been proved to reduce the resistance of cancerous cells to antineoplastic drugs by inhibiting transporter proteins of the ATP-binding cassette (ABC) type. This phenomenon is often responsible for the failure of chemotherapy [116]. Among neurologic diseases, masitinib has been studied in Alzheimer's dementia and MS, and some clinical trials are currently recruiting or completed (clinicaltrial. gov). Mast cells are likely to be crucial actors in the pathogenesis of MS and could be a target of masitinib, which has been proved to be well tolerated in a phase IIa clinical trial [117]. In Alzheimer's dementia, masitinib blocked the Fyn protein, a kinase involved in the signals 
Table 1 Investigational anti-inflammatory drugs. The name of the drugs, their mechanism of action, and phase of clinical study are reported in the table

\begin{tabular}{|c|c|c|c|}
\hline $\begin{array}{l}\text { Product } \\
\text { name }\end{array}$ & Company & Mechanism of action & Phase \\
\hline Masitinib & AB Science & Tyrosine-kinase inhibitor & $\begin{array}{l}\text { Phase III- } \\
\text { active, } \\
\text { not } \\
\text { recruiting }\end{array}$ \\
\hline NP001 & $\begin{array}{l}\text { Neuraltus } \\
\text { Pharmaceuti- } \\
\text { cals }\end{array}$ & $\begin{array}{l}\text { Modulation of monocyte } \\
\text { activation and } \\
\text { downregulation of } \\
\text { NF-kB in macrophages }\end{array}$ & $\begin{array}{l}\text { Phase II- } \\
\text { recruiting }\end{array}$ \\
\hline Fingolimod & $\begin{array}{l}\text { ALS Therapy } \\
\text { Development } \\
\text { Institute }\end{array}$ & $\begin{array}{l}\text { Sphingosine-1-phosphate } \\
\text { receptor modulator }\end{array}$ & $\begin{array}{l}\text { Phase II- } \\
\text { complet- } \\
\text { ed }\end{array}$ \\
\hline RNS 60 & Ravalesio Inc & $\begin{array}{l}\text { Modulator of PI3K-Akt } \\
\text { pathway }\end{array}$ & $\begin{array}{l}\text { Phase I- } \\
\text { recruiting } \\
\text { Phase II } \\
\text { start date: } \\
\text { January } \\
2018\end{array}$ \\
\hline Tocilizumab & Genentech, Inc. & $\begin{array}{l}\text { mAb blocking IL- } 6 \text { re- } \\
\text { ceptor }\end{array}$ & $\begin{array}{l}\text { Phase } \mathrm{II}- \\
\quad \text { recruiting }\end{array}$ \\
\hline Anakinra & $\begin{array}{l}\text { Swedish } \\
\text { Orphan } \\
\text { Biovitrum } \\
\text { AB }\end{array}$ & IL-1 receptor antagonist & $\begin{array}{l}\text { Phase II- } \\
\text { complet- } \\
\text { ed }\end{array}$ \\
\hline Ibudilast & $\begin{array}{l}\text { MediciNova } \\
\text { Inc. }\end{array}$ & $\begin{array}{l}\text { Nonselective } \\
\text { phosphodiesterase } \\
\text { (PDE) inhibitor }\end{array}$ & $\begin{array}{l}\text { Phase II- } \\
\text { recruiting }\end{array}$ \\
\hline GW2580 & Calbiochem & $\begin{array}{l}\text { CSF1R tyrosine-kinase } \\
\text { inhibitor }\end{array}$ & $\begin{array}{l}\text { Preclinical } \\
\text { phase }\end{array}$ \\
\hline Pioglitazone & $\begin{array}{l}\text { Takeda Pharma } \\
\text { GmbH }\end{array}$ & $\begin{array}{l}\text { Peroxisome } \\
\text { proliferator-activated } \\
\text { receptor Y (PPARY) } \\
\text { agonist }\end{array}$ & $\begin{array}{l}\text { Phase II- } \\
\text { complet- } \\
\text { ed }\end{array}$ \\
\hline Celecoxib & $\begin{array}{l}\text { Pharmacia, } \\
\text { Gaithersburg, } \\
\text { MD }\end{array}$ & $\begin{array}{l}\text { Cyclooxygenase- } 2 \\
(\mathrm{COX}-2) \text { inhibitor }\end{array}$ & $\begin{array}{l}\text { Phase II- } \\
\text { terminat- } \\
\quad \text { ed }\end{array}$ \\
\hline Celastrol & Generic & $\begin{array}{l}\text { Antioxidant triterpene- } \\
\text { suppresses TNF- } \alpha \text {, } \\
\text { IL-1 } \beta \text {, and iNOS and } \\
\text { induces heat shock } \\
\text { protein response }\end{array}$ & $\begin{array}{l}\text { Preclinical } \\
\text { phase }\end{array}$ \\
\hline AM-1241 & $\begin{array}{l}\text { Tocris } \\
\quad \text { Bioscience }\end{array}$ & $\begin{array}{l}\text { Selective cannabinoid } \\
\text { receptor } 2 \text { (CB2) ago- } \\
\text { nist }\end{array}$ & $\begin{array}{l}\text { Preclinical } \\
\text { phase }\end{array}$ \\
\hline Folic acid & Generic & $\begin{array}{l}\text { Methyl donor-reduces } \\
\text { homocysteine levels }\end{array}$ & $\begin{array}{l}\text { Preclinical } \\
\text { phase }\end{array}$ \\
\hline
\end{tabular}

downstream of amyloid $\beta$ plaques, and reduced the symptoms in a murine model [118]. Masitinib also decreased ischemic brain area and neurological deficits in rat models of postischemic stroke through the inhibition of the plateletderived growth factor receptors (PDGFR) [119]. Preclinical experiments with masitinib have been performed. Oral therapy with masitinib initiated 7 days after the occurrence of paralysis in mSOD1 rats diminished gliosis and exerted a neuroprotective effect on MNs [111]. This therapeutic regimen with masitinib increased postparalysis survival time by $40 \%$ ( 7 days).

A multicenter, phase II/III, double-blind clinical trial randomized 394 ALS patients to three experimental arms, two of them receiving 4.5 and $3 \mathrm{mg} / \mathrm{kg}$ of masitinib daily for 48 weeks, while the third group was the placebo control group (ClinicalTrials.gov Identifier: NCT02588677). All participants were taking riluzole $50 \mathrm{mg}$ and they must have been on riluzole therapy for at least 30 days before screening. According to the results of the interim analysis, collected in April 2016 and based on data gathered from about 50\% $(n=$ 191) of the enrolled patients who completed the 48 weeks' therapy, masitinib seems to have met both its primary and secondary endpoint. The first was a change in the ALS

function rating scale revised (ALSFRS-R) score, while the latter included respiratory function (forced vital capacity or FVC) and combined assessment of function and survival (CAFS). The dose used in this trial was below the maximum tolerated pharmacologic dose, which has not been clearly established yet, although pharmacokinetic data demonstrated a linear rising of the maximum serum concentration [C(max)] and of the area under curve (AUC) in a dose-dependent fashion [120]. Masitinib received orphan drug designation for ALS from the Food and Drug Administration (FDA) and the European Medical Agency (EMA). Apparently, the side effect profile was relatively satisfactory, while long-term side effects consisted in gastrointestinal, hematological, and dermatological manifestation and other systemic symptoms [112]. Recently, a case of autoimmune-like hepatitis has been reported in a patient with ALS who received masitinib for 6 months: transaminases and bilirubin kept increasing for 9 weeks after discontinuation of the drug. Other tyrosine-kinase inhibitors have been associated with drug-induced liver injury, but this is the first case of liver injury caused by masitinib to date [121]. In September 2016, AB Science applied for marketing authorization of masitinib in ALS at EMA.

On March 20,2017, AB Science disclosed the results of the final analysis of the trial (Source: AB Science press release). The final analysis was based on data gathered from 394 patients and confirmed the positive results of the interimanalysis regarding efficacy and safety. Indeed, the effects on change in ALSFRS-R score, progression-free survival, and patients' quality of life were statistically significant. Furthermore, the final analysis confirmed the safety profile of masitinib. The estimated completion date of the trial is June 2017.

\section{AV411 or MN-166 (Ibudilast)}

AV411 (or MN-166) is a relatively nonselective inhibitor of phosphodiesterase (PDE), available in an oral formulation and initially employed to treat asthma [122], along with first-line drugs suchas steroids, $\beta 2$-agonists, and leukotriene inhibitors. 


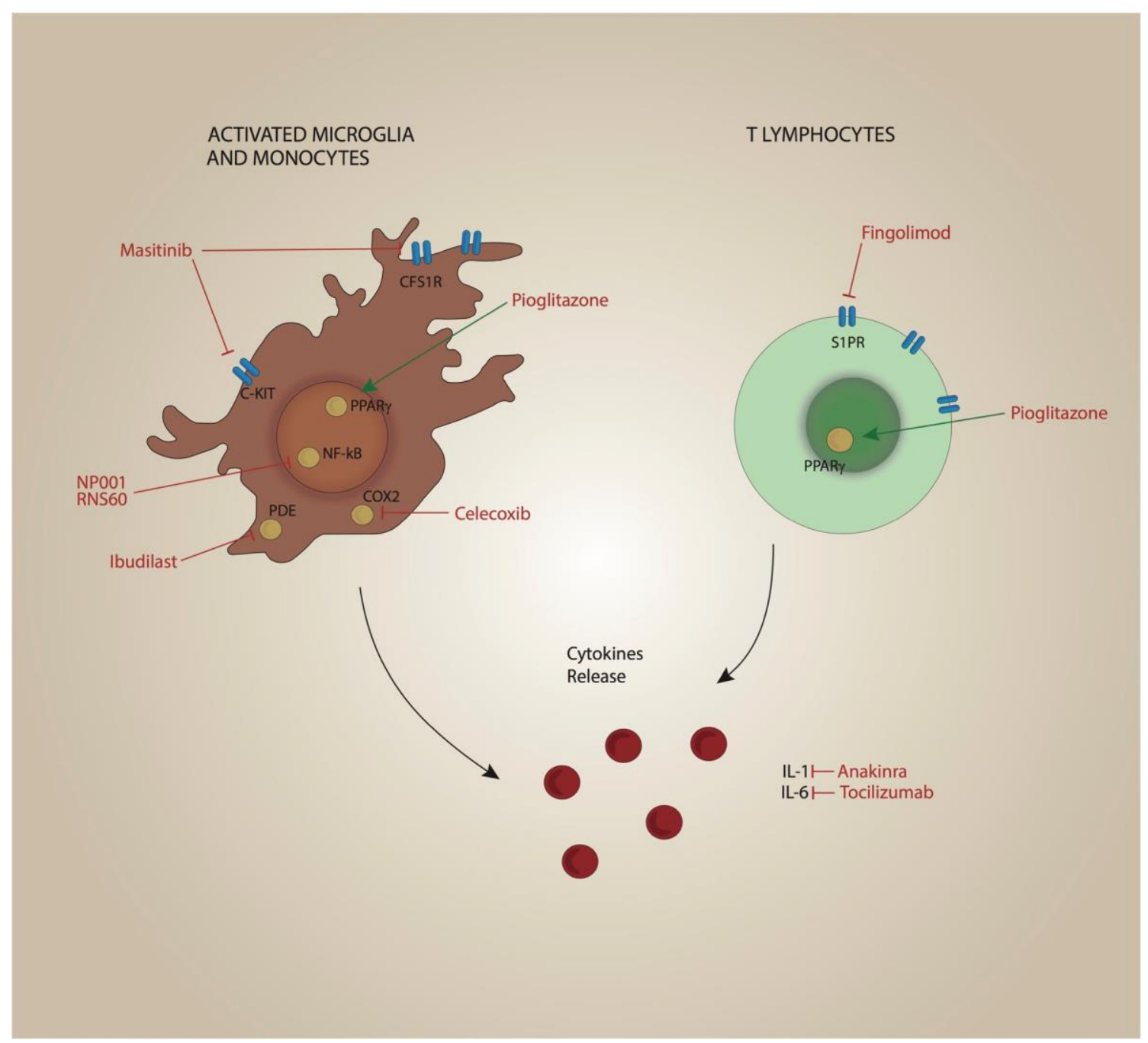

Fig. 2 Experimental drugs and their cellular and molecular target. Antiinflammatory drugs studied in clinical trials can act predominantly on microglial cells and monocytes (masitinib, NP001, RNS60, ibudilast, celecoxib) or on T lymphocytes (fingolimod) or act on different cellular targets simultaneously (pioglitazone). By blocking different signaling

The role of ibudilast in reducing the release of leukotrienes, cytokines, and other molecules involved in bronchospasm [123] and inflammation is the basis for its indication as an anti-asthmatic medication [124, 125]. Furthermore, ibudilast seemed to be a useful treatment in poststroke dizziness, probably because of its vasodilator effect.

Further studies have shown that ibudilast could also attenuate inflammation in the CNS. MN-166 modulates survival and activation of immune cells [126] by preventing the production of pro-inflammatory agents from resident immune cells such as microglia $[127,128]$. At the same time, it modulates how resident and peripheral immune cells interact with each other. It modulates the release of migration inhibitory factor (MIF), a strong pro-inflammatory molecule, which limits the activity of both peripheral and central macrophages. The results obtained studying animal models of autoimmune pathways or enzymes, these anti-inflammatory drugs can also decrease the production and release of pro-inflammatory and cytotoxic cytokines. Other anti-inflammatory drugs act by blocking the action of proinflammatory cytokines (anakinra and tocilizumab), thus decreasing pro-inflammatory signals and inflammation-induced neurotoxicity

encephalomyelitis [129], cerebrovascular white matter lesions due to chronic microglial activation [130], and Krabbe's disease [131] have proved a globally favorable impact. This supports a possible beneficial role of ibudilast in neurological disorders [132] in which glial dysregulation has been demonstrated to contribute to pathogenesis and progression [133].

Initially, ibudilast has been tested in MS. A phase 2, multicenter, double-blind trial has been conducted on 297 patients affected by MS who showed a relapsing clinical pattern and with contrast-enhancing lesions at the magnetic resonance imaging (MRI). Patients have been randomized in three groups receiving respectively 30 or $60 \mathrm{mg}$ of ibudilast or placebo on a daily regimen for a period of 12 months. The primary endpoint was the total number of new active brain lesions visible at the MRI obtained every 2 months over the study period, while the secondary endpoints considered the rate of relapse, 
modification in the Expanded Disability Status Scale (EDSS) score, the volume of lesions seen as hyperintense in T2weighted MRIs and hypointense in T1-weighted MRI sequences, and the percentage change in brain volume. This trial has proved that the drug was safe and well tolerated but it has not met the primary or the secondary endpoints, reasonably suggesting that ibudilast had no impact on the course of disease. On the other hand, a neuroprotective role of this molecule could have been detected in limiting brain atrophy and damage after acute inflammatory injury [134]. A multicenter, randomized controlled trial [ClinicalTrials.gov Identifier: NCT01982942] is currently ongoing to assess whether the drug is safe and tolerated and test its activity in 250 subjects diagnosed with either primary progressive or secondary progressive forms of MS, who are not undergoing long-term treatment with MS disease-modifying medications or who are treated with either glatiramer acetate or IFN- $\beta$. In the latter case, the drug is administered in combination. Randomization into two treatment groups is based on disease status and immune-modulating therapy status. The experimental drug (ibudilast $100 \mathrm{mg} /$ day or placebo) is administered twice daily over 96 weeks. The pharmacological activity of the drug will be assessed at a time point of 96 weeks through the evaluation of the degree of atrophy of the entire brain using MRI and the evaluation of its overall safety and tolerability. The secondary endpoints are the examination of CNS structures via different MRI measures and the evaluation of disability, cognitive impairment, quality of life, and neuropathic pain. This trial could also highlight any possible interaction with eventually coadministered immune modulators.

Two trials on humans are now ongoing to evaluate the efficacy of ibudilast in ALS. The first is an open-label, single center phase II trial of MN-166 on ALS patients $(n=15)$ that is currently being carried out at Massachusetts General Hospital [ClinicalTrials.gov Identifier: NCT02714036]. The main purpose of this study is to evaluate the impact of ibudilast on inflammation in the CNS measured by imaging techniques. The study consists in a screening phase of 6 weeks followed by an open-label treatment phase of 36 weeks with $100 \mathrm{mg} /$ day of ibudilast and a 4 -week follow-up phase after the discontinuation of ibudilast. The primary endpoint includes the quantification of the drug uptake in the motor cortex and in the brain stem by PET imaging at 24 weeks and the effect of ibudilast on blood markers of inflammation, such as TNF- $\alpha$, IFN- $\gamma$, IL-1, IL-6, and IL-10. The secondary outcome measures are safety, tolerability, the impact of the drug on motor function expressed as ALSFRS-R score, slow vital capacity (SVC), and hand-held dynamometry (HHD) as measures of the global respiratory function. At the same time, a phase II double-blind, placebo-controlled trial is ongoing and recruiting at Carolinas Healthcare System (ClinicalTrials.gov Identifier: NCT02238626). Its aim is to assess the general safety and tolerability profile and the clinical response to a daily dosage of $60 \mathrm{mg}$ of ibudilast, in combination with riluzole $(100 \mathrm{mg} /$ day $)$, after a 6 -month therapy. Sixty patients are randomly assigned to two experimental groups, receiving respectively MN-166 or placebo. Both groups will undergo a 3 -month screening phase followed by a double-blind phase of 6 months for the MN-166 group, an open-label follow-up of 6 months only for the placebo control group, and a 2-week follow-up after the discontinuation of the drug. A periodic evaluation is performed at 3 and 6 months, while telephonic contacts will occur at 1,2, 4, and 5 months to notice potential effects of concomitant medications or side effects. The primary endpoint is safety and tolerability of the drug when administered in association with riluzole, while the secondary outcome is the activity of MN-166 on disease progression, muscle strength, and respiratory function evaluated with the following scales or occurrence of clinical event: ALSFRS-R, SVC, maximum inspiratory pressure (MIP) and forced expiratory volume in the 1st second (FEV1), manual muscle testing (MMT), hand grip dynamometry, and the requirement of noninvasive ventilation (NIV). Even though these clinical trials on ALS patients are still at an early phase, the results of the use of ibudilast in MS allow us to hope in a potential effect in ALS, at least in combination with other molecules or the currently approved therapy.

\section{NP001}

Immunomodulatory therapy targeting monocytes/macrophages is the rationale of the use of NP001, produced by Neuraltus Pharmaceuticals, Inc. NP001 is a pH-adjusted formulation of sodium chlorite, available for IV administration, that is converted to taurine chloramine within monocytes and macrophages. It can regulate the function of monocytes both in vivo and in vitro by downregulating NF-kB expression, thus inhibiting the production of IL- $1 \beta$. This inhibition causes a switch in monocytes from an inflammation-promoting phenotype to a basal, noninflammatory phenotype [135]. Safety, tolerability, and preliminary efficacy of NP001 have been assessed in a phase II, double-blind, placebo-controlled study (ClinicalTrials.gov Identifier: NCT01281631) [136]. The results were published in 2015. The study enrolled 136 patients who were randomly divided into three groups (1:1: 1 ), receiving respectively 1 or $2 \mathrm{mg} / \mathrm{kg}$ or placebo in a total of 20 infusions over 6 cycles. The primary outcome of efficacy was expressed as ALSFRS-R score after 6 months of treatment, while secondary endpoints were tolerability and safety, change in pulmonary function, and other measures of patients' status such as survival and time to tracheotomy. At the beginning of each treatment cycle and after 6 months, plasma concentration of biomarkers of inflammation such as C-reactive protein (CRP) and monocyte chemoattractant protein 1 (MCP-1) were obtained. At the end of the study, other biomarkers of activation of macrophages to a pro-inflammatory 
state such as IL-1, IL-18, IL-6, TNF- $\alpha$, IFN- $\gamma$, LPS, and CRP were also quantified. The trial demonstrated that NP001 was generally safe and tolerated while the most common adverse effects were dizziness and infusion site pain, both of which had a higher incidence in the group receiving the higher dose regimen. Although $25 \%$ of patients that were assigned to the high dosage regimen did not show clinical signs of progression over 6 months, compared to $11 \%$ of patients who received the placebo, the trial failed to prove that NP001 could alter the progression of disease $(p=0.55)$. It is to note that the study was underpowered due to small sample size, as pointed out by the authors. It is also important to highlight that 70 to $80 \%$ of responders in the two groups receiving the NP001 formulation had elevated baseline markers of inflammation and that these markers, such as LPS and IL-18, decreased after treatment. This observation supports the fact that NP001 could be helpful and show a greater efficacy in slowing the progression of disease in a subset of patients who show relevant systemic neuroinflammation. In August 2016, Neuraltus Pharmaceuticals, Inc. initiated a phase II randomized, double-blind, placebo-controlled, multicenter study of NP001 in ALS patients (ClinicalTrials.gov Identifier: NCT02794857). Interestingly, inclusion criteria for this trial include a high concentration of CRP at screening with the aim to include only patients with elevated systemic inflammation. The primary endpoint of this study is the change in the ALSFRS$\mathrm{R}$ score from baseline, while secondary outcomes are change in pulmonary function, time to tracheotomy, and change in the levels of blood markers of inflammation. The estimated primary completion date is September 2017.

\section{Drugs Targeting Lymphocytes}

\section{FTY720 (Fingolimod)}

FTY720 (fingolimod), the first approved oral drug for the treatment of relapsing-remitting MS [FDA, 2010, 2015], is a modulator of the sphingosine-1-phosphate (S1P) receptor [137]. The phosphorylated form of FTY720 causes the internalization and degradation of the S1P receptors, leading to the retention of lymphocytes to secondary lymphoid organs and the subsequent reduction of circulating naïve and central memory $\mathrm{T}$ cells [138]. Effector memory $\mathrm{T}$ cells are spared, thus preserving peripheral immune surveillance. The lipophilic characteristic of this compound makes it capable of crossing the blood-brain barrier and acting directly on CNS-resident cells where S1P receptors, except for S1P receptor 4, are highly expressed [139]. In vitro studies have demonstrated that FTY720 reduced the production of pro-inflammatory mediators in activated microglial cells in a dose-dependent manner by acting as a $\mathrm{S} 1 \mathrm{P}$ receptor agonist. At the same time, it increased the production of neurotrophic factors such as BDNF and GDNF [140]. Animal models of brain ischemia [141], epilepsy [142], and spinal cord damage [143] have showed a reduction of neuronal damage and microglial activation after treatment with FTY720, confirming the antiinflammatory and neuroprotective properties of fingolimod. The primary effect of the drug on toxic neuronal death has been proved in cellular and animal models. Cultures of neurons without contact with the peripheral immune system and exposed to toxic concentrations of NMDA have showed a dose-dependent decrease in neuronal death after a prolonged treatment with fingolimod. The protective effect has been confirmed in vivo [144]. The toxicity due to the excess of excitatory stimuli is a crucial mechanism involved in ALS. Therefore, FTY720 seems to be a promising therapeutic drug because of its ability to act on at least two different processes involved in MN disease.

Recently, it has been described that treatment with fingolimod can improve the outcome of SOD1 murine model of ALS [145]; 0.1 or $1 \mathrm{mg} / \mathrm{kg}$ i.p. doses of fingolimod were administered to animals during the whole course of disease. The compound led to a significant improvement of clinical signs and survival rate of mSOD1 mice, even if only of 1015 days. The positive effects have been linked to the modulation of inflammatory genes (CD11b, Foxp3, iNOS, IL-1 $\beta$, IL10 , Arg1, and BDNF) in the CNS. These findings suggest that fingolimod could have a beneficial effect in ALS.

A phase IIA clinical trial, assessing the safety and tolerability of this molecule on ALS patients (ClinicalTrials.gov Identifier: NCT01786174), has been recently completed and the results should soon be published. The study enrolled 28 ALS patients, 18 of which received the treatment. The drug was administered for a short time span (28 days). No major safety issue was detected. ALSFRS-R score did not change significantly at 8 weeks (based on the data reported on clinicaltrial.gov), but the drug was administered only for 1 month.

Some adverse effects have been reported in MS patients both during clinical trials and postmarketing surveillance. Alterations in heart rate, especially bradycardia, were caused by the action of fingolimod on S1P receptors expressed on atrial myocytes and required the patient to be monitored for at least $6 \mathrm{~h}$ during the administration of the first dose [146]. A reduction of the number of lymphocytes up to $70 \%$ was another effect of the drug but was completely reversible after 6 weeks. Mild infections of the upper and lower airways were common but serious events were rare. A case of disseminated varicella zoster virus (VZV) infection and other severe herpes virus infections have been reported, thus making the serologic screening for VZV and the vaccination of antibody-negative patients necessary prior to treatment. Cases of cryptococcal meningitis and progressive multifocal encephalitis (PML) have been described. Finally, before and during the therapy, 
an examination of fundus oculi could be required for early detection of macular edema, especially during the first 4 months [147].

Given these results and the fact that fingolimod has both direct and indirect neuroprotective effects, the next step would be a phase IIB/III clinical trial to test its efficacy and long-term safety.

\section{Drugs Targeting Cytokines}

Other inflammatory pathways have been proved to play a role in neuronal loss in ALS [3] and have been further investigated as pharmacological targets. Different compounds that can inhibit cytokines directly or indirectly have been investigated.

\section{Anakinra}

IL-1 has been shown to be particularly unregulated in response to the presence of mSOD1 [148]. The mutant protein induces the activation of a component of the cytosolic protein complex inflammosome [149] called caspase-1, a protein that is also necessary for IL-1 $\beta$ to be converted to its mature form through a proteolytic mechanism [148]. IL-1 stimulates macrophages and microglia in a dose-related fashion, leading to the acquisition of a pro-inflammatory phenotype and ultimately to inflammation-related neurotoxicity [17]. A study conducted by Meissner et al. [150] has demonstrated that the uptake of mSOD1 had a higher efficiency than that of the WT SOD1 and led to its cytoplasmic accumulation. mSOD1 can form oligomers that resemble those formed by amyloid protein, as described either in vitro and in animal models, and the misfolding degree was linked to IL- $1 \beta$ maturation and faster disease progression. In the same study, Meissner and colleagues have shown that the deficiency of IL-1 $\beta$ and caspase- 1 and the treatment with the antagonist of the IL-1 receptor slowed disease progression in mice, providing further evidence that IL-1 could be a suitable therapeutic target.

A single-arm pilot study [151] (ClinicalTrials.gov Identifier: NCT01277315) has been conducted in Berlin at Charité University Hospital to assess safety and tolerability of the IL-1 receptor antagonist anakinra, a drug currently used to treat rheumatoid arthritis [152]. The results were published in 2015. Anakinra was administered in association with riluzole in ALS patients, and disease progression was measured using ALSFRS$\mathrm{R}$ and forced expiratory vital capacity as secondary endpoint. Serum markers of inflammation such as IL- 6 and TNF- $\alpha$ were also measured. Assuming that anakinra could reach a higher concentration in peripheral nerves, the study was designed to enroll only patients who showed predominantly or exclusively signs of degeneration of lower MNs (LMNs), even if there is evidence that anakinra can reach therapeutic concentration in the CNS [153]. Patients were enrolled at an early stage of disease (mean ALSFRS-R $=40.7$ and mean delta ALSFRS-R $=0.35$, mean age $=57.9$ years old ) and had no sign of hypoventilation syndrome at baseline. The 52-week treatment with anakinra, $100 \mathrm{mg}$ daily, was completed by 17 patients. Anakinra was generally safe, with the most common adverse effect being reaction at the site of injection, which occurred with increased frequency and intensity over the course of the study. Infections of the respiratory tract occurred in seven patients and resolved without the need of antimicrobial therapy. Fifteen patients were also screened for mutation in the SOD1 and C9ORF72 genes, in the attempt to identify a link between the genotype and the response to the treatment with anakinra. Only four patients were found to have the expansion of the hexanucleotide repeat (with 1700 repeat or more) in C9ORF72 and did not show any difference in the response to the treatment or any apparent sign of dementia compared to the rest of the group. The study did not prove any difference in disease progression, although the trial did not have sufficient power to show any statistically relevant difference and lacked a placebo control group. IL- 6 and TNF- $\alpha$ levels were not significantly altered at the end of the treatment, but cytokine levels were measured only in plasma and not in the cerebrospinal fluid. It is otherwise relevant that 16 out of 17 patients developed anti-anakinra IgG after a mean of 4 weeks after treatment. These antibodies can halt the drug from acting on its target. The study proved the general safety and tolerability of anakinra and justifies further placebo-controlled studies on a broader cohort of patients to prove efficacy.

\section{Tocilizumab}

Another immunomodulatory drug, tocilizumab, is currently being studied for the treatment of ALS. Tocilizumab is a monoclonal antibody, currently approved to treat rheumatoid arthritis and juvenile idiopathic arthritis. It blocks the IL-6 receptor thus exerting a neuroprotective effect by decreasing cytokine production and the activation of the immune system. The in vitro efficacy of tocilizumab in reducing inflammation has been assessed by a pilot study [154]. Another study [155] has tested the effect of tocilizumab in sALS patients and has shown that the effects of Actrema ${ }^{R}$ on inflammation were different in the two groups of patients. It reduced inflammation, as shown by downregulation of inflammatory genes as IL-1 $\beta$, in patients who had strong baseline inflammation (eight key genes showed a more than 4-fold increased expression, $p<0.05$ ), while it slightly increased inflammation in the second group which showed weak baseline inflammation. A phase 2 randomized, placebo-controlled trial is currently ongoing (ClinicalTrials.gov Identifier: NCT02469896), and its primary endpoint is to assess safety and tolerability of tocilizumab over a 16-week time frame, while evaluation of the expression of pro-inflammatory genes in monocytes from peripheral blood is the secondary endpoint. Patients are treated with $8 \mathrm{mg} / \mathrm{kg}$ tocilizumab infusion or placebo every 4 weeks for 3 months. The trial is currently recruiting participants and 
the estimated completion date is August 2017. No update is available to date.

However, recent preclinical studies have revealed that the knockout of the IL- 6 gene had no effect in modifying the outcome of mSOD1 mice [156]. The same has been observed with the pharmacological block of IL-6 through a murine analogous of tocilizumab, namely MR16-1 [157]. A significant increase in weight loss has been reported as a negative effect of MR16-1, despite amoderate anti-inflammatory effect.

These studies support the targeting of monocyte/ macrophage activation as a strategy to slow the progression of disease but only in patients who show increased systemic inflammation and dysregulated activation of macrophages. This highlights that it could be needed to identify this subset of patients for this approach to be suitable. However, the possible negative effects observed in preclinical models represent a caveat for this approach.

\section{Other Anti-inflammatory Drugs}

RNS60: Charge-Stabilized Nanoparticles in Oxygen-Saline Solution

RNS60 has been proposed as a novel approach to attenuate NF-kB activation and the associated activation of glial cells.

RNS60 consists of a saline solution $(0.9 \% \mathrm{NaCl})$ containing charge-stabilized nanostructures or nanobubbles, which have been shown to decrease inflammation and cell death. RNS60 is generated by subjecting normal saline solution to Taylor-Couette-Poiseuille flow under high oxygen pressure.

Nanobubbles were applied for the first time in the late 1990s by Tony Wood to increase plants' resistance to diseases. Thereafter, its therapeutic use for human diseases has been suggested.

RNS60 has been found to inhibit the production of $\mathrm{NO}$ and the expression of iNOS in activated microglia. It has been hypothesized that RNS60 could carry out its antiinflammatory action by inhibiting NF-kB through the activation of type IA phosphatidylinositol 3-kinase (PI3K) and the phosphorylation of Akt protein. The latter would subsequently upregulate IKB $\alpha$, which blocks NF-kB, ultimately preventing iNOS expression and the production of $\mathrm{NO}$ and neurotoxins [158]. iNOS upregulation has been related to MN loss and overactivation of microglia and astrocytes. Therefore, it has been proposed that the inhibition of iNOS could represent a fruitful direction to explore new therapeutic agents for neurodegenerative disorders [159]. It has been shown that RNS60 could enhance ATP synthesis by facilitating oxygen transport into the mitochondrial system in Xenopus laevis oocytes and on squid synapses [160].

Recently, positive effects of RNS60 have been reported on Alzheimer's disease, both in vitro and in the 5XFAD transgenic mouse model, by augmenting the expression of neuronal plasticity-associated proteins and AMPA-/NMDAdependent hippocampal calcium inflow [161]. It also decreased neuron apoptosis, tau phosphorylation, and glial activation and the amount of amyloid tangles [162]. RNS60 has been reported to be a potential disease modulator in Parkinson's disease [163] and MS [164], improving neurotransmission [165] and neuroprotection on one hand while acting on the immune response on the other.

Preclinical studies on RNS60 toxicity have shown little or no side effects and three phase I clinical trials have provided satisfactory data on tolerability of inhaling and intravenous administration.

To date, an open-label phase I clinical trial is ongoing at Massachusetts General Hospital focusing on safety, tolerability, and efficacy in a group of ALS patients (ClinicalTrials.gov Identifier: NCT02525471). Inclusion criteria encompass riluzole naïve patients and patients who have not been on riluzole therapy for at least 30 days. The study combines the previously tested way of administration with a 7-day scheme for 24 weeks. Evaluation of the main endpoints will involve the measurement of blood biomarkers of inflammation, neuroimaging analysis (PET), and the assessment of the clinical outcome by testing of pulmonary function (SVC), strength (test of limb isometric strength), and functional status (ALSFRS-R).

Although the real biological impact of this compound is controversial, we are further concerned by the fact that RNS60 is basically saline solution. This raises doubt about the ethical basis of this trial and if the study should have been allowed to proceed to a phase II study.

\section{Pioglitazone}

Pioglitazone belongs to the class of thiazolidinediones and acts as a peroxisome proliferator-activated receptor $\mathrm{Y}$ (PPARY) agonist [166]. Pioglitazone is currently used as an oral antidiabetic drug because it increases sensitivity to insulin and decrease glycemia. The PPARs are nuclear hormone receptors which present several isoforms. Isoforms share the major structural and functional properties but can show different ligand specificities and tissue distribution. For example, PPARa expression is predominant in the liver, skeletal muscle, kidney, heart, and vascular wall, while PPARY is primarily found in adipose tissue, intestine, and macrophages. The activation of this class of receptors modulates the expression of several genes and influences the cellular response to different stimuli such as metabolic alterations or inflammation [167]. Interestingly, PPARs have been shown to regulate the inflammatory response by reducing the release of the proinflammatory cytokines TNF- $\alpha$, IL- $1 \beta$, and IL-6. PPARs have been reported to upregulate the expression of iNOS and metalloproteases in mononuclear and epithelial cells. Furthermore, PPARs inhibit various transcription factors and promote the expression of NF-KB, signal transducers and activators 
of transcription (STATs), activator protein 1 (AP1), and nuclear factor of activated T cells (NFAT) [168]. Such effects have been demonstrated to be induced by PPAR $\alpha$ thanks to the availability of PPARa knockout animal models [169]. Since the absence of PPARy is not compatible with life, it is not possible to create a similar animal model. Consequently, the PPARa-induced antiinflammatory effects have not been confirmed to be induced also by PPARy. However, additional studies have been performed in vitro, using cerebellar granule cells and mononuclear cells $[170,171]$, and in vivo [172]. These studies have strongly suggested a pivotal role of PPARY in attenuating inflammationrelated neurotoxicity. Three independent groups have tested pioglitazone, the only molecule able to extensively penetrate the blood-brain barrier, in mSOD1 mice [173-175]. Since inflammation has been identified as an early event in disease pathogenesis, the treatment with oral pioglitazone was started before the onset of clinical signs. Treated animals have shown prolonged survival, decreased weight loss, and delayed decline in motor function compared to untreated mice. Neuropathological studies have demonstrated extended survival of MNs, which preserved their structural and functional properties, as well as a significant decrease in microglial activation. A reduced expression of two major pro-inflammatory enzymes cyclooxygenase-2 (COX-2) and iNOS and an increased expression of the anti-inflammatory genes SOCS-1 and SOCS-3 have been confirmed by Western blot analysis. The expression of SOD1 was not affected by the treatment. These promising results have encouraged the design of a phase II, multicenter, stratified, parallel-group, placebocontrolled trial to test the potential efficacy of pioglitazone in ALS patients who already received riluzole (ClinicalTrials.gov Identifier: NCT00690118) [176]. The primary endpoint of the trial was survival. The secondary endpoints included incidence of NIV and tracheotomy, decline of motor function measured as ALS-FRS-R score, modifications in SVC, and quality of life. Patients were matched for age, sex, type of disease onset, and functional and metabolic status. Patients were randomly assigned to two groups: one receiving placebo and the other one receiving pioglitazone. Unfortunately, on April 2010, the trial was terminated because of the increased number of deaths among the treated patients. However, further analyses have demonstrated that such deaths were not caused by pioglitazone. In fact, pioglitazone was globally well-tolerated. The failure of this clinical trial has been attributed to the fact that the drug should have been administered before the disease onset, as inpreclinical studies.

\section{COX-2 Inhibitors: Celecoxib}

The COX-2 enzyme has been reported to play an important role in the pathogenesis of ALS. COX-2 catalyzes the synthesis of prostaglandins (PGs), especially PGE2, which are directly involved in glutamate-mediated neurotoxicity and inflammation. Specifically, PGE2 promotes the release of glutamate from astroglial cells via a calcium-dependent pathway, feeding the mechanism of impaired glutamate turnover detected in ALS [177, 178]. Furthermore, COX-2 contributes to the inflammatory process by favoring the production of neurotoxins, cytokines, and free radicals. COX-2 inhibitors, like celecoxib, have already been approved by the FDA for the treatment of arthritis and have been suggested to have a potential therapeutic effect in ALS. These observations have been supported by the fact that high levels of COX-2 and PGE2 have been detected in the cerebrospinal fluid and in the spinal cord of mSOD1 mice and of patients affected by sALS [179, 180]. The oral administration of celecoxib in mSOD1 mice has obtained promising results. The treatment with celecoxib extended the survival rate and prevented weight loss and motor function decline. Reduced expression of PGE2 in the spinal cord of treated animals has been demonstrated by neuropathological analysis [181]. A randomized, double-blind, placebo-controlled trial has been conducted to test the clinical effect of celecoxib in ALS [8]. The trial has been prematurely terminated because preliminary statistical analyses have showed no difference between the celecoxib and the placebo-treated groups. In fact, neither the primary nor the secondary endpoints have been met. Also, PGE2 levels in the cerebrospinal fluid have showed no changes between the two groups. The authors have claimed that PGE2 levels were not properly dosed because of unreliable biochemical tools.

Other Anti-inflammatory Compounds: Celastrol, AM-1241, and Folic Acid

Over the years, several well-known anti-inflammatory compounds have been tested for the treatment of ALS. Celastrol is a triterpine, a natural extracted molecule which is traditionally used in Southern China for its potent anti-inflammatory and neuroprotective effects. Celastrol has been shown to suppress the release of cytokines, decrease glial activation, and promote the synthesis of heat shock proteins (HSPs), especially HSP70 [182]. Preclinical studies have tested a 4-week treatment with celastrol in mSOD1 mice. Such studies have confirmed the ability of the drug to downregulate TNF- $\alpha$ expression and glial activity and to upregulate HSP70 expression and prevent the early loss of MNs in the spinal cord. Treated mice showed a delayed disease onset, slower motor function decline, and prolonged survival compared to controls [183].

Despite such promising results, no sufficient data on the safety of the drug and its capacity to penetrate the blood-brain barrier have been collected to date. Therefore, further studies are needed before celastrol could proceed to testing in humans [184].

The role of endocannabinoids in ALS pathogenesis is still controversial. They have been demonstrated to prevent the death of neuronal cells induced by excitotoxicity or oxidative damage and to have anti-inflammatory properties [185]. The selective activation of the cannabinoid receptor 2 (CB2) by 
AM-1241 has demonstrated a positive effect against inflammatory hyperalgesia in animal models [186]. The first studies of AM-1241 in mSOD1 mice have demonstrated no psychotropic effect of the drug and a sex-dependent delay in the motor function impairment. Delayed motor function decline has been reported even if the treatment was started after the onset of the symptoms. No effect on weight loss and survival has been reported [187].

The upregulation of the CB2 receptors in glial cells and spinal cord specimens has been described in tissue samples from ALS patients [188]. Shoemaker's group has detected a significant increase of the CB2 receptor density in tissue samples from mSOD1 mice. The density of the CB2 receptor varied as the disease progressed, thus suggesting an early neuroprotective effect of such receptors [189].

Furthermore, a significant extension of life span has been obtained after the injection of AM-1241 in symptomatic mSOD1 mice. Despite these positive results, the exact role of endocannabinoids in ALS and the mechanism of action of compounds that bind to $\mathrm{CB}$ receptors remain to be elucidated. AM-1241 has been proposed to act as a Bprotean agonist $\wedge$ displaying a different mechanism of action, depending on the assay and/or tissue examined [190].

Folic acid has been evaluated for its ability to reduce the levels of homocysteine, which have been found to be elevated in astrocyte-derived ALS animal models [191]. It is still debated how homocysteine could be involved in the pathogenesis of ALS. However, its role in promoting inflammation and inducing cytokine release and excitotoxicity has been largely demonstrated [192]. Good preclinical data have been obtained from the treatment of mSOD1 mice with acid folic. Treated animals exhibited a delayed disease onset and an extended survival. Furthermore, a reduction of both $\mathrm{MN}$ degeneration and pro-inflammatory cytokine expression has been detected by histopathological and biochemical analysis [193]. Despite the good results obtained in the preclinical setting, we believe that the simple supplementation of folic acid would not have the same effects in humans. For this reason, we do not encourage the translation of this approach to clinical trial in humans.

\section{Molecules in Preclinical Stages}

Role of IL-10

Inflammation is a constant phenomenon in ALS and involves both systemic and CNS alterations in the immune response. In the CNS of ALS subjects, reactive astrocytes, activated microglia, levels of cytokines, and inflammatory mediators are typically increased.

Several in vitro and in vivo studies have shown that reactive microgliosis represents not only a hallmark of ALS but also correlates with the severity of $\mathrm{MN}$ degeneration. The clinical onset of the disease could depend on what type of cytokines is predominately expressed. Gravel et al. [194] have demonstrated that, in two mSOD1 murine models ( $S O D 1^{G 93 A}$ and $S O D 1^{G 37 R}$ mice), microglial cells overexpress IL-10 during the presymptomatic phase of disease. The overexpression of IL-10 via viral vectors has been shown to slow the progression of disease and increase survival, while the opposite has been demonstrated by blocking this pathway with an anti-IL10 receptor antibody.

Although it is a very fascinating and investigated aspect, the role of T cells in the pathogenesis and progression of ALS is not clear yet. There is evidence that microglial activation could have a toxic effect on neuronal progenitor by blocking their differentiation, while the activation of $\mathrm{T}$ cells could promote neurodifferentiation [195]. However, it is still unknown whether $\mathrm{T}$ lymphocytes are the primary inducers of microglia activation or vice versa. They could be just bystanders and be recalled to the site of inflammation by the death of neurons and chemokines released by resident cells [196].

\section{Colony-Stimulating Factor 1 Receptor Inhibitor}

CSF1R (or CD115) is a transmembrane receptor for IL-34 and colony-stimulating factor 1 (CSF1) and belongs to the type III growth factor receptor family with tyrosine-kinase activity. Signaling through this receptor leads to the activation of a downstream mitogenic pathway sustained by the activity of PU.1 and CCAAT/enhancer binding protein (C/EBPa) [197], a pathway that contributes to the maturation of microglia and monocytes and to hematopoiesis [198]. There is evidence that this pathway is among those involved in developing and maintaining the inflammatory response and the subsequent damage to neurons [199].

A recent study [200] on a mouse model of prion disease supported the role of CSF1R in microglial proliferation across different areas of the brain. This effect increased as the disease progressed and positively correlated with the progressively higher expression of CSF1 and CSF1R mRNAs. In the same study, GW2580, a CSF1R inhibitor, was shown to decrease the expression of CSF1R, PU.1, and C/ECBa and of the downstream effectors of this pathway cyclins D1 and D2. GW2580 also increased the acquisition of an M2 microglial phenotype. The block of microglial expansion resulted in slower disease progression, decreased number of damaged neurons, improved survival rate, and delayed onset of behavioral symptoms.

The same effect of the treatment with GW2580 has been shown in animal models of MS [201] and of Alzheimer's disease [202].

A preclinical study on mSOD1 mice has showed beneficial effects of GW2580 on disease progression and survival rate [203]. The inhibition of CSF1R reduced the number of microglial cells in the spinal cord by $30 \%$ and increased the 
number of viable MNs at a late stage of disease compared to untreated mice. The results have been confirmed by fluorescence-activated cell sorting (FACS) and immunohistochemical analysis. Decreased levels of the transcription factors PU-1, IRF8, and RUNX1 have been detected. These transcription factors are involved in microglial maturation and proliferation. Furthermore, the cell cycle regulator cyclin D2 acts downstream of CSF1R. However, the treatment with GW2580 had no significant effect on the expression of the 11 cytokines investigated. The inhibition of this pathway has been proved to increase motor function and survival and delay the progression of the disease. No effect on disease onset has been observed. Instead, the impact on peripheral nerves was consistent, as suggested by the reduction of monocytes in the tibial nerve of treated mSOD1 mice, probably due to a 2.5 fold depletion of blood monocytes after treatment. The improvement in the peripheral nervous system could be beneficial to motor impairment by slowing early muscle denervation even before any measurable reduction in microglial proliferation. In fact, the upregulation of CSF1 R has not been observed at an early stage of disease, suggesting that its role could be limited to a later stage. However, consistent microgliosis has been found to be an early mark of neurodegeneration and to be likely driven by the activation of other signaling pathways, some of which were previously discussed.

In contrast with the previously discussed studies on CSF1R, a study on a murine model of Alzheimer's disease has reported a favorable impact of the administration of human recombinant CSF1 and IL-34 and of the deletion of CSF1R in the forebrain on neuron survival and memory performance [204]. As reported by the authors, this could be due to the limited expression of CSF1R in a small group of cortical and hippocampal neurons under physiological conditions, while the receptor seems to be almost exclusively expressed by microglia in the CNS.

This evidence supports further studies on the role of the CSF1R signaling pathway in neurodegeneration, especially in ALS. The targeting of CSF1R could be evaluated as a therapeutic strategy for future trials on humans.

\section{Novel Promising Molecular Targets}

\section{TANK Binding Kinase 1 (TBK1)}

TBK1 is a serine/threonine kinase that plays an essential role in regulating the inflammatory response. When activated, this protein associates with TRAF3 and TANK and phosphorylates different IFN regulatory factors (IRFs). Phosphorylated IRFs can undergo homodimerization and translocate to the nucleus to activate the transcription of pro-inflammatory and antiviral genes such as IFN- $\alpha$ and IFN- $\beta$.
Recently, TBK1 has been implicated in the regulation of autophagy and inflammation. Mutations in the TBKl gene have been recognized to cause ALS, frontotemporal dementia (FTD) [205], normal tension glaucoma (NTG), or childhood herpes simplex encephalitis (HSE) [206]. In particular, mutations that cause the abnormal activation of TBK1 have been linked to NTG, while mutations that abolish its function lead to ALS/FTD or HSE. Genetic mutations that alter the signaling process between the TLR3 and IFN [207], like those in $T B K 1$, have been shown to negatively affect IFN- $\gamma$ levels and to be correlated with the onset of HSE in a group of children. Autophagy dysfunctions caused by loss of TBK1 [208] have also been described as possible underlying causes of ALS/ FTD, but the possible perturbation of neuroinflammatory pathways should also be considered as potential therapeutic target in this case.

\section{RIPK1}

It has been recently described that optineurin (OPTN), the protein encoded by one of the ALS causative genes, inhibits the signaling downstream of RIPK1 by modulating its turnover [209]. RIPK1 is recruited to the TNFR1 receptor and consequently mediates TNF- $\alpha$-mediated neurotoxicity. The lack of OPTN causes a gradual demyelination and progressive axonal damage by activating necroptosis signals, comprising RIPK1, RIPK3, and MLKL. RIPK1- and RIPK3-linked axonal damage has been detected in $\mathrm{Optn}^{-/-}$mice, in mSOD1 mice, and in tissue samples from ALS patients. Therefore, RIPK1 and RIPK3 are likely to exert a significant action on axonal degeneration. Ito et al. [209] have also demonstrated that the increased activation of RIPK1 in $\mathrm{Optn}^{-/-}$mice caused an increased activation of microglial cells toward an M1 phenotype in the spinal cord and increased the secretion of proinflammatory factors like TNF- $\alpha$, IFN- $\gamma$, IL-1, IL-2, and IL12. This suggests that the lack of OPTN and the impaired turnover of RIPK1 could induce neuronal injury either by causing axonal degeneration and necroptosis and increasing microglia-induced inflammation. To further confirm the involvement of this cell death pathway in vivo, the authors studied the effects of RIPK1 inhibition through the generation of $\mathrm{Optn}^{-/-} ;$RipkI $^{\text {DI38N/D138N }}$ double mutant mice or the pharmacological inhibition of the RIPK1 kinase activity with Nec-1 in $\mathrm{Optn}^{-/-}$or mSOD1 mice. Either genetic disruption or pharmacological inhibition of RIPK1 activity rescued hind limb weakness and axonal pathology of $\mathrm{Optn}^{-/-}$mice, as well as axonal pathology and degeneration in mSOD1 mice. Furthermore, the myelination defects observed in mSOD1 mice were rescued by knockdown of Ripk3. Given these results, the inhibition of RIPK1 could represent a suitable strategy to rescue MNs from TNF- $\alpha$-mediated death. Because RIPK1 has been shown to be specifically recruited by TNFR1 and modulate the negative effect of TNF- $\alpha$, it has 
been suggested that targeting RIPK1 could have a beneficial effect without involving TNFR2. Based on this evidence, the inhibition of the RIPK1 kinase activity could represent a promising strategy to slow or even stop the axonal injury and to improve MN function in ALS. Since an effective pharmacological inhibitor of RIPK1 is available, we encourage further in vivo studies with Nec-1 to confirm its efficacy and safety in ALS. These data would be helpful for a foreseeable application of Nec-1 in humans.

\section{Conclusions}

While no effective therapy for ALS is currently available, inflammation has come to light as an active injury mechanism and a new suitable target for a therapeutic effort. To date, many different molecules and antibodies have been tested in clinical trials, targeting astrocytes, microglial cells, monocytes, T cells, and cytokine pathways. Even though there is no major concern on the safety of all the studied drugs, almost all of them showed moderate or no efficacy in the phase II clinical trials that have been concluded, while others are still ongoing. Only masitinib has been proved to have a modest effect on motor performance. The final analysis of the phase II/III trial of masitinib in ALS patients has confirmed the positive results of the interim analysis and has proved that masitinib was effective in improving motor function, progression-free survival, and quality of life of patients. It is noteworthy that the studies that tested NP001, anakinra, and tocilizumab were not sufficiently powered to show a statistically relevant outcome. Furthermore, the trial that has been conducted with tocilizumab supported the fact that not all patients may present a strong inflammatory component. Therefore, this kind of approach could be consistently helpful for a relatively small group of patients. However, the identification of patients who have a strong baseline inflammation is still limited to subjects enrolled in a small number of clinical trials, thus making difficult to estimate the percentage of patients with a strong inflammatory component compared to all ALS cases. We suggest that recognizing this group of patients would be helpful to know what percentage of ALS subjects would be more likely to benefit from an anti-inflammatory treatment and would also allow to select a homogeneous group of patients for clinical trials. Moreover, this would permit to recognize if increased systemic inflammation is more frequent in subjects with fALS or sALS or if it could be associated with certain genetic mutations.

Immune modulation and promotion of an antiinflammatory phenotype in microglia and $\mathrm{T}$ cells seems to be a relatively unexplored field to modify the course of this disease. Further studies could prove a positive impact of this strategy.
A considerable issue that emerged is the relatively frequent failure of clinical trials to replicate the results obtained in the animal model. Preclinical studies on ALS almost invariably employ the mSOD1 transgenic murine model (generally the $S O D 1^{\mathrm{G} 93 \mathrm{~A}}$ mouse model). Despite being a useful model for research, it is now clear that it is also a limited one. In fact, patients who harbor a recognized pathogenic mutation in the SOD1 gene represent a very limited subgroup of all ALS patients. Moreover, the ALS phenotype showed by these mice is greatly dependent on four factors: gender, genetic background, SOD1 mutation, and expression levels of the human SOD1 transgene [210]. The standard SOD ${ }^{\mathrm{G} 93 \mathrm{~A}}$ mouse model carries 25 copies of the $\mathrm{mSOD} 1$ transgene under the control of the human SOD1 promoter [211], but it is known that loss of several transgene copies can occur spontaneously during meiosis [210]. This phenomenon can lead to a variable phenotype expression and cause a variable degree of severity and response to treatment [212]. The same phenomenon can occur in mice carrying a human $S O D 1$ transgene with a different mutation. Since the SOD $1^{\mathrm{G} 93 \mathrm{~A}}$ mouse model is the most used one, the effects of different SODI mutations can be generally overlooked. The issue of the variable genetic background is more challenging because many genetic variations could modify the severity, the time of onset, and the progression of disease [213]. Further studies aimed to improve the available animal models of ALS or MN degeneration could help to improve the preclinical screening of novel therapeutic compounds.

Based on what is known about neuroinflammation and CNS-resident immune cells, we highlight that the NF-kB pathway seems to be particularly relevant for inflammationinduced neurotoxicity. The activation of NF-kB likely represents the converging point of several damage signals and could be a particularly fruitful target for therapeutics. However, this approach would likely require the precise target of NF-kB into microglial cells and astrocytes to have a significant impact.

Even if no major change in ALS progression has been achieved by targeting inflammation, some of the compounds undergoing preclinical investigation could have the potentiality to exert a meaningful impact on the disease and could be easily applied in clinical settings. Also, the discovery of novel molecular mechanisms warrants further investigation toward the development of an effective therapy for ALS. Wepostulate that a deeper knowledge of the molecules and cellular pathways involved in neuronal damage could lead to the selection and design of efficient therapies.

Based on the data presented herein, targeting inflammation in ALS would certainly have a weaker impact on the disease than a possible therapy directed against its pathogenic causes. However, we think that the development of efficient antiinflammatory or immune-modulating therapies would at least lead to symptomatic improvement or to a relatively short 
increase in survival, which would provide an acceptable clinical improvement for ALS patients. This possibility supports further efforts to improve this approach, since no pathogenic therapy is available to date.

Acknowledgments Joint Programme Neurodegenerative Disease (JPND) Research grant DAMNDPATHS ${ }^{\wedge}$ (2014) and ARISLA grant smallRNALS^ (2014) to SC and the Italian Ministry of Health RF2013-023555764 and Regione Lombardia TRANS-ALS to GPC are gratefully acknowledged. We thank Associazione Amici del Centro Dino Ferrari for its support.

\section{References}

1. Bucchia M, Ramirez A, Parente V, Simone C, Nizzardo M, Magri F, Dametti S, Corti S (2015) Therapeutic development in amyotrophic lateral sclerosis. Clin Ther 37(3):668-680. doi:10.1016/j. clinthera.2014.12.020

2. Ajroud-Driss S, Siddique T(2015) Sporadic and hereditary amyotrophic lateral sclerosis (ALS). Biochim Biophys Acta 1852(4): 679-684. doi:10.1016/j.bbadis.2014.08.010

3. McGeer PL, McGeer EG(2002) Inflammatory processes in amyotrophic lateral sclerosis. Muscle Nerve 26(4):459-470. doi:10. 1002/mus.10191

4. Malaspina A, Puentes F, Amor S (2015) Disease origin and progression in amyotrophic lateral sclerosis: an immunology perspective. Int Immunol27(3):117-129. doi:10.1093/intimm/dxu099

5. Hooten KG, Beers DR, Zhao W, Appel SH (2015) Protective and toxic neuroinflammation in amyotrophic lateral sclerosis. Neurotherapeutics 12(2):364-375. doi:10.1007/s13311-0140329-3

6. Clement AM, Nguyen MD, Roberts EA, Garcia ML, Boillee S, Rule M, McMahon AP, Doucette W et al (2003) Wild-type nonneuronal cells extend survival of SOD1 mutant motor neurons in ALS mice. Science 302(5642):113-117. doi:10.1126/science. 1086071

7. Graves MC, Fiala M, Dinglasan LA, Liu NQ, Sayre J, Chiappelli F, van Kooten C, Vinters HV (2004) Inflammation in amyotrophic lateral sclerosis spinal cord and brain is mediated by activated macrophages, mast cells and T cells. Amyotroph Lateral Scler Other Motor Neuron Disord 5(4):213-219

8. Cudkowicz ME, Shefner JM, Schoenfeld DA, Zhang H, Andreasson KI, Rothstein JD, Drachman DB (2006) Trial of celecoxib in amyotrophic lateral sclerosis. Ann Neurol 60(1): 22-31. doi:10.1002/ana.20903

9. Goyal NA, Mozaffar T (2014) Experimental trials in amyotrophic lateral sclerosis: a review of recently completed, ongoing and planned trials using existing and novel drugs. Expert Opin Investig Drugs 23(11):1541-1551. doi:10.1517/13543784.2014. 933807

10. Mitsumoto H, Brooks BR, Silani V (2014) Clinical trials in amyotrophic lateral sclerosis: why so many negative trials and how can trials be improved? Lancet Neurol 13(11):1127-1138. doi:10. 1016/s1474-4422(14)70129-2

11. Scott S, Kranz JE, Cole J, Lincecum JM, Thompson K, Kelly N, Bostrom A, Theodoss J et al (2008) Design, power, and interpretation of studies in the standard murine model of ALS. Amyotroph Lateral Scler 9(1):4-15. doi:10.1080/17482960701856300

12. Orrell RW, Lane RJ, Ross M (2008) A systematic review of antioxidant treatment for amyotrophic lateral sclerosis/motor neuron disease. Amyotroph Lateral Scler 9(4):195-211. doi:10.1080/ 17482960801900032
13. Smith SA, Miller RG, Murphy JR, Ringel SP (1994) Treatment of ALS with high dose pulse cyclophosphamide. J Neurol Sci 124(Suppl):84-87

14. Werdelin L, Boysen G, Jensen TS, Mogensen P (1990) Immunosuppressive treatment of patients with amyotrophic lateral sclerosis. Acta Neurol Scand 82(2):132-134

15. Meininger V, Drory VE, Leigh PN, Ludolph A, Robberecht W, Silani V (2009) Glatiramer acetate has no impact on disease progression in ALS at $40 \mathrm{mg} /$ day: a double-blind, randomized, multicentre, placebo-controlled trial. Amyotroph Lateral Scler 10(5-6):378-383. doi:10.3109/17482960902803432

16. Rizzo F, Riboldi G, Salani S, Nizzardo M, Simone C, Corti S, Hedlund E (2014) Cellular therapy to target neuroinflammation in amyotrophic lateral sclerosis. Cell Mol Life Sci 71(6):9991015. doi:10.1007/s00018-013-1480-4

17. Philips T, Robberecht W (2011) Neuroinflammation in amyotrophic lateral sclerosis: role of glial activation in motor neuron disease. Lancet Neurol 10(3):253-263. doi:10.1016/s1474-4422(11) 70015-1

18. Radford RA, Morsch M, Rayner SL, Cole NJ, Pountney DL, Chung RS (2015) The established and emerging roles of astrocytes and microglia in amyotrophic lateral sclerosis and frontotemporal dementia. Front Cell Neurosci:9. doi:10.3389/ fncel.2015.00414

19. Brettschneider J, Toledo JB, Van Deerlin VM, Elman L, McCluskey L, Lee VM, Trojanowski JQ (2012) Microglial activation correlates with disease progression and upper motor neuron clinical symptoms in amyotrophic lateral sclerosis. PLoS One 7(6):e39216. doi:10.1371/journal.pone.0039216

20. Turner MR, Cagnin A, Turkheimer FE, Miller CC, Shaw CE, Brooks DJ, Leigh PN, Banati RB (2004) Evidence of widespread cerebral microglial activation in amyotrophic lateral sclerosis: an $[11 \mathrm{C}](\mathrm{R})-\mathrm{PK} 11195$ positron emission tomography study. Neurobiol Dis 15(3):601-609. doi:10. 1016/j.nbd.2003.12.012

21. Albrecht DS, Granziera C, Hooker JM, Loggia ML (2016) In vivo imaging of human neuroinflammation. ACS Chem Neurosci 7(4): 470-483. doi:10.1021/acschemneuro.6b00056

22. Quartuccio N, Van Weehaeghe D, Cistaro A, Jonsson C, Van Laere K, Pagani M (2014) Positron emission tomography neuroimaging in amyotrophic lateral sclerosis: what is new? Q J Nucl Med Mol Imaging 58(4):344-354

23. Vivash L, O'Brien TJ (2016) Imaging microglial activation with TSPO PET: lighting up neurologic diseases? J Nucl Med 57(2): 165-168. doi:10.2967/jnumed.114.141713

24. Zurcher NR, Loggia ML, Lawson R, Chonde DB, IzquierdoGarcia D, Yasek JE, Akeju O, Catana C et al (2015) Increased in vivo glial activation in patients with amyotrophic lateral sclerosis: assessed with [(11)C]-PBR28. Neuroimage Clin 7:409-414. doi:10.1016/j.nicl.2015.01.009

25. Tang D, Kang R, Coyne CB, Zeh HJ, Lotze MT (2012) PAMPs and DAMPs: signal 0s that spur autophagy and immunity. Immunol Rev 249(1):158-175. doi:10.1111/j.1600-065X.2012. 01146.x

26. Gordon S, Martinez FO (2010) Alternative activation of macrophages: mechanism and functions. Immunity 32(5):593-604. doi: 10.1016/j.immuni.2010.05.007

27. Zhao W, Xie W, Xiao Q, Beers DR, Appel SH (2006) Protective effects of an anti-inflammatory cytokine, interleukin-4, on motoneuron toxicity induced by activated microglia. J Neurochem 99(4):1176-1187. doi:10.1111/j.1471-4159.2006.04172.x

28. Beers DR, Zhao W, Liao B, Kano O, Wang J, Huang A, Appel SH, Henkel JS (2011) Neuroinflammation modulates distinct regional and temporal clinical responses in ALS mice. Brain Behav Immun 25(5):1025-1035. doi:10.1016/j.bbi.2010.12.008 
29. Moisse K, Strong MJ (2006) Innate immunity in amyotrophic lateral sclerosis. Biochim Biophys Acta 1762(11-12):10831093. doi:10.1016/j.bbadis.2006.03.001

30. Allodi I, Comley L, Nichterwitz S, Nizzardo M, Simone C, Benitez JA, Cao M, Corti S et al (2016) Differential neuronal vulnerability identifies IGF-2 as a protective factor in ALS. Scientific reports 6:25960. doi:10.1038/srep25960

31. Dodge JC, Haidet AM, Yang W, Passini MA, Hester M, Clarke J, Roskelley EM, Treleaven CM et al (2008) Delivery of AAV-IGF-1 to the CNS extends survival in ALS mice through modification of aberrant glial cell activity. Mol Ther 16(6):1056-1064. doi:10. 1038/mt.2008.60

32. Brohawn DG, O'Brien LC, Bennett JP Jr (2016) RNAseq analyses identify tumor necrosis factor-mediated inflammation as a major abnormality in ALS spinal cord. PLoS One 11(8):e0160520. doi: 10.1371/journal.pone.0160520

33. Zhou Z, Peng X, Hagshenas J, Insolera R, Fink DJ, Mata M (2010) A novel cell-cell signaling by microglial transmembrane TNFalpha with implications for neuropathic pain. Pain 151(2): 296-306. doi:10.1016/j.pain.2010.06.017

34. Dong Y,Fischer R, Naude PJ, Maier O, Nyakas C, Duffey M, Van der Zee EA, Dekens D et al (2016) Essential protective role of tumor necrosis factor receptor 2 in neurodegeneration. Proc Natl Acad Sci U S A 113(43):12304-12309. doi:10.1073/pnas. 1605195113

35. Chen G, Goeddel DV (2002) TNF-R1 signaling: a beautiful pathway. Science 296(5573):1634-1635. doi:10.1126/science. 1071924

36. Depuydt B, van Loo G, Vandenabeele P, Declercq W (2005) Induction of apoptosis by TNF receptor 2 in a T-cell hybridoma is FADD dependent and blocked by caspase- 8 inhibitors. J Cell Sci 118(Pt 3):497-504. doi:10.1242/jcs.01640

37. Kaltsonoudis E, Voulgari PV, Konitsiotis S, Drosos AA (2014) Demyelination and other neurological adverse events after antiTNF therapy. Autoimmun Rev 13(1):54-58. doi:10.1016/j.autrev. 2013.09.002

38. Kuno R, Wang J, Kawanokuchi J, Takeuchi H, Mizuno T, Suzumura A (2005) Autocrine activation of microglia by tumor necrosis factor-alpha. J Neuroimmunol 162(1-2):89-96. doi:10. 1016/j.jneuroim.2005.01.015

39. Taylor DL, Jones F, Kubota ES, Pocock JM (2005) Stimulation of microglial metabotropic glutamate receptor mGlu2 triggers tumor necrosis factor alpha-induced neurotoxicity in concert with microglial-derived Fas ligand. J Neurosci 25(11):2952-2964. doi:10.1523/jneurosci.4456-04.2005

40. Takeuchi H, Jin S, Wang J, Zhang G, Kawanokuchi J, Kuno R, Sonobe Y, Mizuno T et al (2006) Tumor necrosis factor-alpha induces neurotoxicity via glutamate release from hemichannels of activated microglia in an autocrine manner. J Biol Chem 281(30):21362-21368. doi:10.1074/jbc.M600504200

41. Olmos G, Llado J (2014) Tumor necrosis factor alpha: a link between neuroinflammation and excitotoxicity. Mediat Inflamm 2014:861231. doi:10.1155/2014/861231

42. Zou JY, Crews FT (2005) TNF alpha potentiates glutamate neurotoxicity by inhibiting glutamate uptake in organotypic brain slice cultures: neuroprotection by NF kappa B inhibition. Brain Res 1034(1-2):11-24. doi:10.1016/j.brainres.2004.11.014

43. Sitcheran R, Gupta P, Fisher PB, Baldwin AS (2005) Positive and negative regulation of EAAT2 by NF-kappaB: a role for $\mathrm{N}$-myc in TNFalpha-controlled repression. EMBO J 24(3):510-520. doi:10. 1038/sj.emboj.7600555

44. Tilleux S, Hermans E (2007) Neuroinflammation and regulation of glial glutamate uptake in neurological disorders. J Neurosci Res 85(10):2059-2070. doi:10.1002/jnr.21325

45. Howland DS, Liu J, She Y, Goad B, Maragakis NJ, Kim B, Erickson J, Kulik J et al (2002) Focal loss of the glutamate transporter EAAT2 in a transgenic rat model of SOD1 mutantmediated amyotrophic lateral sclerosis (ALS). Proc Natl Acad Sci U S A 99(3):1604-1609. doi:10.1073/pnas.032539299

46. Rothstein JD, Van Kammen M, Levey AI, Martin LJ, Kuncl RW (1995) Selective loss of glial glutamate transporter GLT-1 in amyotrophic lateral sclerosis. Ann Neurol 38(1):73-84. doi:10. 1002/ana.410380114

47. Gelbard HA, Dzenko KA, DiLoreto D, del Cerro C, del Cerro M, Epstein LG (1993) Neurotoxic effects of tumor necrosis factor alpha in primary human neuronal cultures are mediated by activation of the glutamate AMPA receptor subtype: implications for AIDS neuropathogenesis. Dev Neurosci 15(6):417-422

48. Jara JH, Singh BB, Floden AM, Combs CK (2007) Tumor necrosis factor alpha stimulates NMDA receptor activity in mouse cortical neurons resulting in ERK-dependent death. J Neurochem 100(5):1407-1420. doi:10.1111/j.1471-4159.2006.04330.x

49. Zhen Y, Ding C, Sun J, Wang Y,Li S, Dong L (2016) Activation of the calcium-sensing receptor promotes apoptosis by modulating the JNK/p38 MAPK pathway in focal cerebral ischemiareperfusion in mice. Am J Transl Res 8(2):911-921

50. Walker DG, Lue LF (2015) Immune phenotypes of microglia in human neurodegenerative disease: challenges to detecting microglial polarization in human brains. Alzheimers Res Ther vol 7. vol 1. doi:10.1186/s13195-015-0139-9

51. Shin WH, Lee DY, Park KW, Kim SU, Yang MS, Joe EH, Jin BK (2004) Microglia expressing interleukin-13 undergo cell death and contribute to neuronal survival in vivo. Glia 46(2):142-152. doi: 10.1002/glia. 10357

52. Gordon S (2003) Alternative activation of macrophages. Nat Rev Immunol 3(1):23-35. doi:10.1038/nri978

53. Colton CA (2009) Heterogeneity of microglial activation in the innate immune response in the brain. J NeuroImmune Pharmacol 4(4):399-418. doi:10.1007/s11481-009-9164-4

54. Ponomarev ED, Maresz K, Tan Y, Dittel BN (2007) CNS-derived interleukin- 4 is essential for the regulation of autoimmune inflammation and induces a state of alternative activation in microglial cells. J Neurosci 27(40):10714-10721. doi:10.1523/jneurosci. 1922-07.2007

55. Lyons A, Downer EJ, Crotty S, Nolan YM, Mills KH, Lynch MA (2007) CD200 ligand receptor interaction modulates microglial activation in vivo and in vitro: a role for IL-4. J Neurosci 27(31):8309-8313. doi:10.1523/jneurosci.1781-07.2007

56. Morris SM Jr (2004) Recent advances in arginine metabolism. Curr Opin Clin Nutr Metab Care 7(1):45-51

57. Thomas T, Thomas TJ (2001) Polyamines in cell growth and cell death: molecular mechanisms and therapeutic applications. Cell Mol Life Sci 58(2):244-258. doi:10.1007/p100000852

58. Jenkins CL, Bretscher LE, Guzei IA, Raines RT (2003) Effect of 3-hydroxyproline residues on collagen stability. J Am Chem Soc 125(21):6422-6427. doi:10.1021/ja034015j

59. Busch SA, Silver J (2007) The role of extracellular matrix in CNS regeneration. Curr Opin Neurobiol 17(1):120-127. doi:10.1016/j. conb.2006.09.004

60. Bronte V,Zanovello P (2005) Regulation of immune responses by L-arginine metabolism. Nat Rev Immunol 5(8):641-654. doi:10. 1038/nri1668

61. Tang Y,Li T, Li J, Yang J, Liu H, Zhang XJ, Le W (2014) Jmjd3 is essential for the epigenetic modulation of microglia phenotypes in the immune pathogenesis of Parkinson's disease. Cell Death Differ 21(3):369-380. doi:10.1038/cdd.2013.159

62. Roberts K, Zeineddine R, Corcoran L, Li W, Campbell IL, YerburyJJ (2013) Extracellular aggregated Cu/Zn superoxide dismutase activates microglia to give a cytotoxic phenotype. Glia 61(3):409-419. doi:10.1002/glia.22444

63. Casula M, Iyer AM, Spliet WG, Anink JJ, Steentjes K, Sta M, Troost D, Aronica E (2011) Toll-like receptor signaling in 
amyotrophic lateral sclerosis spinal cord tissue. Neuroscience 179: 233-243. doi:10.1016/j.neuroscience.2011.02.001

64. De Paola M, Mariani A, Bigini P, Peviani M, Ferrara G, Molteni M, Gemma S, Veglianese P et al (2012) Neuroprotective effects of toll-like receptor 4 antagonism in spinal cord cultures and in a mouse model of motor neuron degeneration. Mol Med 18:971981. doi:10.2119/molmed.2012.00020

65. Lee JY, Lee JD, Phipps S, Noakes PG, Woodruff TM (2015) Absence of toll-like receptor 4 (TLR4) extends survival in the hSOD1 G93A mouse model of amyotrophic lateral sclerosis. J Neuroinflammation 12:90. doi:10.1186/s12974-015-0310-Z

66. Jou I, Lee JH, Park SY, Yoon HJ, Joe EH, Park EJ (2006) Gangliosides trigger inflammatory responses via TLR4 in brain glia. Am J Pathol 168(5):1619-1630. doi:10.2353/ajpath.2006. 050924

67. Tang SC, Arumugam TV, Xu X, Cheng A, Mughal MR, Jo DG, Lathia JD, Siler DA et al (2007) Pivotal role for neuronal Toll-like receptors in ischemic brain injury and functional deficits. Proc Natl Acad Sci U S A 104(34):13798-13803. doi:10.1073/pnas. 0702553104

68. Fitzgerald KA, Palsson-McDermottEM, Bowie AG, Jefferies CA, Mansell AS, Brady G, Brint E, Dunne A et al (2001) Mal (MyD88-adapter-like) is required for Toll-like receptor-4 signal transduction. Nature 413(6851):78-83. doi:10.1038/35092578

69. Frakes AE,FerraiuoloL, Haidet-Phillips AM,SchmelzerL, Braun L, Miranda CJ, Ladner KJ, Bevan AK et al (2014) Microglia induce motor neuron death via the classical NF-kappaB pathway in amyotrophic lateral sclerosis. Neuron 81(5):1009-1023. doi:10. 1016/j.neuron.2014.01.013

70. Swarup V, Phaneuf D, Dupre N, Petri S, Strong M, Kriz J, Julien JP(2011) Deregulation of TDP-43 in amyotrophic lateral sclerosis triggers nuclear factor kappaB-mediated pathogenic pathways. J Exp Med 208(12):2429-2447. doi:10.1084/jem.20111313

71. Uranishi H, Tetsuka T, Yamashita M, Asamitsu K, Shimizu M, Itoh M, Okamoto T (2001) Involvement of the pro-oncoprotein TLS (translocated in liposarcoma) in nuclear factor-kappa B p65mediated transcription as a coactivator. J Biol Chem 276(16): 13395-13401. doi:10.1074/jbc.M011176200

72. Snow WM, Stoesz BM, Kelly DM, Albensi BC (2014) Roles for NF-kappaB and gene targets of NF-kappaB in synaptic plasticity, memory, and navigation. Mol Neurobiol 49(2):757-770. doi:10. 1007/s12035-013-8555-y

73. Kaltschmidt B, Ndiaye D, Korte M, Pothion S, Arbibe L, Prullage M, Pfeiffer J, Lindecke A et al (2006) NF-kappaB regulates spatial memory formation and synaptic plasticity through protein kinase A/CREB signaling. Mol Cell Biol 26(8):2936-2946. doi:10.1128/ mcb.26.8.2936-2946.2006

74. Mattson MP, Culmsee C, Yu Z, Camandola S (2000) Roles of nuclear factor kappaB in neuronal survival and plasticity. J Neurochem 74(2):443-456

75. Abel T, Nguyen PV, Barad M, Deuel TA, Kandel ER, Bourtchouladze R (1997) Genetic demonstration of a role for PKA in the late phase of LTP and in hippocampus-based longterm memory. Cell 88(5):615-626

76. Grilli M, Ribola M, Alberici A, Valerio A, Memo M, Spano P (1995) Identification and characterization of a kappa B/Rel binding site in the regulatory region of the amyloid precursor protein gene. J Biol Chem 270(45):26774-26777

77. Wang JH, Manning BJ, Wu QD, Blankson S, Bouchier-Hayes D, Redmond HP (2003) Endotoxin/lipopolysaccharide activates NFkappa $B$ and enhances tumor cell adhesion and invasion through a beta 1 integrin-dependentmechanism. J Immunol 170(2):795-804

78. Berggard T, Miron S, Onnerfjord P, Thulin E, Akerfeldt KS, Enghild JJ, Akke M, Linse S (2002) Calbindin D28k exhibits properties characteristic of a Ca2+ sensor. J Biol Chem 277(19): 16662-16672. doi:10.1074/jbc.M200415200
79. Odero GL, Oikawa K, Glazner KA, Schapansky J, Grossman D, Thiessen JD, Motnenko A, Ge N et al (2010) Evidence for the involvement of calbindin D28k in the presenilin 1 model of Alzheimer's disease. Neuroscience 169(1):532-543. doi:10. 1016/j.neuroscience.2010.04.004

80. Marini AM, Jiang X, Wu X, Tian F, Zhu D, Okagaki P, Lipsky RH (2004) Role of brain-derived neurotrophic factor and NF-kappaB in neuronal plasticity and survival: from genes to phenotype. Restor Neurol Neurosci 22(2):121-130

81. Kiningham KK, Xu Y, Daosukho C, Popova B, St Clair DK (2001) Nuclear factor kappaB-dependent mechanisms coordinate the synergistic effect of PMA and cytokines on the induction of superoxide dismutase 2. Biochem J 353(Pt 1):147-156

82. Mattson MP, Goodman Y, Luo H, Fu W, Furukawa K (1997) Activation of NF-kappaB protects hippocampal neurons against oxidative stress-induced apoptosis: evidence for induction of manganese superoxide dismutase and suppression of peroxynitrite production and protein tyrosine nitration. J Neurosci Res 49(6): 681-697. doi:10.1002/(sici)1097-4547(19970915)49:6<681::aidjnr3>3.0.co;2-3

83. Ruszkiewicz J, Albrecht J (2015) Changes in the mitochondrial antioxidant systems in neurodegenerative diseases and acute brain disorders. Neurochem Int 88:66-72. doi:10.1016/j.neuint.2014. 12.012

84. Sompol P, Xu Y, Ittarat W, Daosukho C, St Clair D (2006) NFkappaB-associated MnSOD induction protects against betaamyloid-induced neuronal apoptosis. J Mol Neurosci 29(3):279288

85. Sullivan PG, Bruce-Keller AJ, Rabchevsky AG, Christakos S, Clair DK, Mattson MP, Scheff SW (1999) Exacerbation of damage and altered NF-kappaB activation in mice lacking tumor necrosis factor receptors after traumatic brain injury. J Neurosci 19(15):6248-6256

86. Lin CL, Bristol LA, Jin L, Dykes-Hoberg M, Crawford T, Clawson L, Rothstein JD (1998) Aberrant RNA processing in a neurodegenerative disease: the cause for absent EAAT2, a glutamate transporter, in amyotrophic lateral sclerosis. Neuron 20(3): 589-602

87. Dringen R, Pfeiffer B, Hamprecht B (1999) Synthesis of the antioxidant glutathione in neurons: supply by astrocytes of CysGly as precursor for neuronal glutathione. J Neurosci 19(2):562-569

88. RaoulC, Estevez AG, Nishimune H, ClevelandDW, deLapeyriere O, Henderson CE, Haase G, Pettmann B (2002) Motoneuron death triggered by a specific pathway downstream of Fas. Potentiation by ALS-linked SOD1 mutations. Neuron 35(6): 1067-1083

89. Barbeito LH, Pehar M, Cassina P, Vargas MR, Peluffo H, Viera L, Estevez AG, Beckman JS (2004) A role for astrocytes in motor neuron loss in amyotrophic lateral sclerosis. Brain Res Brain Res Rev47(1-3):263-274. doi:10.1016/j.brainresrev.2004.05.003

90. Chen H, Qian K, Chen W, Hu B, Blackbourn LWT, Du Z, Ma L, Liu $\mathrm{H}$ et al (2015) Human-derived neural progenitors functionally replace astrocytes in adult mice. J Clin Invest 125(3):1033-1042. doi:10.1172/jci69097

91. Song S, Miranda CJ, Braun L, Meyer K, Frakes AE, Ferraiuolo L, Likhite S, Bevan AK et al (2016) Major histocompatibility complex class I molecules protect motor neurons from astrocyteinduced toxicity in amyotrophic lateral sclerosis. Nat Med 22(4): 397-403. doi:10.1038/nm.4052

92. Re DB, Le Verche V, Yu C, Amoroso MW, Politi KA, Phani S, Ikiz B, Hoffmann L et al (2014) Necroptosis drives motor neuron death in models of both sporadic and familial ALS. Neuron 81(5): 1001-1008. doi:10.1016/j.neuron.2014.01.011

93. Degterev A, Hitomi J, Germscheid M, Ch'en IL, Korkina O, Teng X, Abbott D, Cuny GD et al (2008) Identification of RIP1 kinase 
as a specific cellular target of necrostatins. Nat Chem Biol 4(5): 313-321. doi:10.1038/nchembio.83

94. Park S, Kim HT, Yun S, Kim IS, Lee J, Lee IS, Park KI (2009) Growth factor-expressing human neural progenitor cell grafts protect motor neurons but do not ameliorate motor performance and survival in ALS mice. Exp Mol Med 41(7):487-500. doi:10.3858/ emm.2009.41.7.054

95. Rizvanov AA, Guseva DS, Salafutdinov II, Kudryashova NV, Bashirov FV, Kiyasov AP, Yalvac ME, Gazizov IM et al (2011) Geneticallymodified humanumbilical cordblood cells expressing vascular endothelial growth factor and fibroblast growth factor 2 differentiate into glial cells after transplantation into amyotrophic lateral sclerosis transgenic mice. Exp Biol Med (Maywood) 236(1):91-98. doi:10.1258/ebm.2010.010172

96. Lepore AC, Rauck B, Dejea C, Pardo AC, Rao MS, Rothstein JD, Maragakis NJ (2008) Focal transplantation-based astrocyte replacement is neuroprotective in a model of motor neuron disease. NatNeurosci 11(11):1294-1301. doi:10.1038/nn.2210

97. Boucherie C, Schafer S, Lavand'homme P, Maloteaux JM, Hermans E (2009) Chimerization of astroglial population in the lumbar spinal cord after mesenchymal stem cell transplantation prolongs survival in a rat model of amyotrophic lateral sclerosis. J Neurosci Res 87(9):2034-2046. doi:10.1002/jnr.22038

98. Chiu IM, Chen A, Zheng Y, Kosaras B, Tsiftsoglou SA, Vartanian TK, Brown RH Jr, Carroll MC (2008) T lymphocytes potentiate endogenous neuroprotective inflammation in a mouse model of ALS. Proc Natl Acad Sci U S A 105(46):17913-17918. doi:10. 1073/pnas.0804610105

99. Beers DR, Henkel JS, Zhao W, Wang J, Appel SH (2008) CD4+ T cells support glial neuroprotection, slow disease progression, and modify glial morphology in an animal model of inherited ALS. Proc Natl Acad Sci U S A 105(40):15558-15563. doi:10.1073/ pnas.0807419105

100. Zhao W, Beers DR, Liao B, Henkel JS, Appel SH (2012) Regulatory T lymphocytes from ALS mice suppress microglia and effector T lymphocytes through different cytokine-mediated mechanisms. Neurobiol Dis 48(3):418-428. doi:10.1016/j.nbd. 2012.07.008

101. Savage ND, de Boer T, Walburg KV, Joosten SA, van Meijgaarden K, Geluk A, Ottenhoff TH (2008) Human antiinflammatory macrophages induce Foxp3+ GITR+ CD25+ regulatory T cells, which suppress via membrane-bound TGFbeta-1. J Immunol 181(3):2220-2226

102. Henkel JS, Beers DR, Wen S, Rivera AL, Toennis KM, Appel JE, Zhao W, Moore DH et al (2013) Regulatory T-lymphocytes mediate amyotrophic lateral sclerosis progression and survival. EMBO Mol Med 5(1):64-79. doi:10.1002/emmm.201201544

103. Nie H, Zheng Y, Li R, Guo TB, He D, Fang L, Liu X, Xiao L et al (2013) Phosphorylation of FOXP3 controls regulatory T cell function and is inhibited by TNF-alpha in rheumatoid arthritis. Nat Med 19(3):322-328. doi:10.1038/nm.3085

104. Li L, Kim J, Boussiotis VA (2010) IL-1beta-mediated signals preferentially drive conversion of regulatory $\mathrm{T}$ cells but not conventional T cells into IL-17-producing cells. J Immunol 185(7): 4148-4153. doi:10.4049/jimmunol.1001536

105. Butovsky O, Siddiqui S, Gabriely G, Lanser AJ, Dake B, Murugaiyan G, Doykan CE, Wu PM et al (2012) Modulating inflammatory monocytes with a unique microRNAgenesignature ameliorates murine ALS. J Clin Invest 122(9):3063-3087. doi:10. 1172/jci62636

106. Chiu IM, Morimoto ET, Goodarzi H, Liao JT, O'Keeffe S, Phatnani HP, Muratet M, Carroll MC et al (2013) A neurodegeneration-specific gene-expression signature of acutely isolated microglia from an amyotrophic lateral sclerosis mouse model. Cell Rep 4(2):385-401. doi:10.1016/j.celrep.2013.06.018
107. Kano O, Beers DR, Henkel JS, Appel SH (2012) Peripheral nerve inflammation in ALS mice: cause or consequence. Neurology 78(11):833-835. doi:10.1212/WNL.0b013e318249f776

108. Mantovani S, Garbelli S, Pasini A, Alimonti D, Perotti C, Melazzini M, Bendotti C, Mora G (2009) Immune system alterationsin sporadic amyotrophic lateral sclerosis patients suggest an ongoing neuroinflammatory process. J Neuroimmunol 210(1-2): 73-79. doi:10.1016/j.jneuroim.2009.02.012

109. Dubreuil P, Letard S, Ciufolini M, Gros L, Humbert M, Casteran N, Borge L, Hajem B et al (2009) Masitinib (AB1010), a potent and selective tyrosine kinase inhibitor targeting KIT. PLoS One 4(9):e7258. doi:10.1371/journal.pone.0007258

110. Paul C, Sans B, Suarez F, Casassus P, Barete S, Lanternier F, Grandpeix-Guyodo C, Dubreuil P et al (2010) Masitinib for the treatment of systemic and cutaneous mastocytosis with handicap: a phase 2a study. Am J Hematol 85(12):921-925. doi:10.1002/ajh. 21894

111. Trias E, Ibarburu S, Barreto-Nunez R, Babdor J, Maciel TT, Guillo M, Gros L, Dubreuil P et al (2016) Post-paralysis tyrosine kinase inhibition with masitinib abrogates neuroinflammation and slows disease progression in inherited amyotrophic lateral sclerosis. J Neuroinflammation 13(1):177. doi:10.1186/s12974-016-0620-9

112. Adenis A, Blay JY, Bui-Nguyen B, Bouche O, Bertucci F, Isambert N, Bompas E, Chaigneau L et al (2014) Masitinib in advanced gastrointestinal stromal tumor (GIST) after failure of imatinib: a randomized controlled open-label trial. Ann Oncol 25(9):1762-1769. doi:10.1093/annonc/mdu237

113. Le Cesne A, Blay JY, Bui BN, Bouche O, Adenis A, Domont J, Cioffi A, Ray-Coquard I et al (2010) Phase II study of oral masitinib mesilate in imatinib-naive patients with locally advanced or metastatic gastro-intestinal stromal tumour (GIST). Eur J Cancer46(8):1344-1351. doi:10.1016/j.ejca.2010.02.014

114. Deplanque G, Demarchi M, Hebbar M, Flynn P, Melichar B, Atkins J, Nowara E, Moye L et al (2015) A randomized, placebo-controlled phase III trial of masitinib plus gemcitabine in the treatment of advanced pancreatic cancer. Ann Oncol 26(6):1194-1200. doi:10.1093/annonc/mdv133

115. Mitry E, Hammel P, Deplanque G, Mornex F, Levy P, Seitz JF, Moussy A, Kinet JP et al (2010) Safety and activity of masitinib in combination with gemcitabine in patients with advanced pancreatic cancer. Cancer Chemother Pharmacol 66(2):395-403. doi:10. 1007/s00280-010-1299-8

116. Wang YJ, Zhang YK, Kathawala RJ, Chen ZS (2014) Repositioning of tyrosine kinase inhibitors as antagonists of ATP-binding cassette transporters in anticancer drug resistance. Cancers (Basel) 6(4):1925-1952. doi:10.3390/cancers6041925

117. Shirani A, Okuda DT, Stuve O (2016) Therapeutic advances and future prospects in progressive forms of multiple sclerosis. Neurotherapeutics 13(1):58-69. doi:10.1007/s13311-015-0409-Z

118. Folch J, Petrov D, Ettcheto M, Abad S, Sanchez-Lopez E, Garcia ML, Olloquequi J, Beas-Zarate C et al (2016) Current research therapeutic strategies for Alzheimer's disease treatment. Neural Plast 2016:8501693. doi:10.1155/2016/8501693

119. Kocic I, Kowianski P, Rusiecka I, Lietzau G, Mansfield C, Moussy A, Hermine O, Dubreuil P (2015) Neuroprotective effect of masitinib in rats with postischemic stroke. Naunyn Schmiedeberg's Arch Pharmacol 388(1):79-86. doi:10.1007/ s00210-014-1061-6

120. Soria JC, Massard C, Magne N, Bader T, Mansfield CD, Blay JY, Bui BN, Moussy A et al (2009) Phase 1 dose-escalation study of oral tyrosine kinase inhibitor masitinib in advanced and/or metastatic solidcancers.EurJCancer45(13):2333-2341.doi:10.1016/ j.ejca.2009.05.010

121. Salvado M, Vargas V, Vidal M, Simon-Talero M, Camacho J, Gamez J (2015) Autoimmune-like hepatitis during masitinib therapy in an amyotrophic lateral sclerosis patient. World J 
Gastroenterol 21(36):10475-10479. doi:10.3748/wjg.v21.i36. 10475

122. Kawasaki A, Hoshino K, Osaki R, Mizushima Y, Yano S (1992) Effect of ibudilast: a novel antiasthmatic agent, on airway hypersensitivity in bronchial asthma. J Asthma 29(4):245-252. doi:10. 3109/02770909209048938

123. Souness JE, Villamil ME, Scott LC, Tomkinson A, Giembycz MA, Raeburn D (1994) Possible role of cyclic AMP phosphodiesterases in the actions of ibudilast on eosinophil thromboxane generation and airways smooth muscle tone. Br J Pharmacol 111(4):1081-1088

124. Ohtsu H, Fujimoto Y, Yamauchi K, Tamura G, Takishima T (1989) Pharmacological effect of KC-404 on leukotriene release from human leukocytes induced by ionophore A23187. Int Arch Allergy Appl Immunol 89(2-3):306-310

125. Choi SH, Sakamoto T, Fukutomi O, InagakiN, Matsuura N, Nagai H, Koda A (1989) Pharmacological study of phospholipase A2induced histamine release from rat peritoneal mast cells. Aust $\mathrm{J}$ Pharm 12(9):517-522

126. Takuma K, Lee E, Enomoto R, Mori K, Baba A, Matsuda T (2001) Ibudilast attenuates astrocyte apoptosis via cyclic GMP signalling pathway in an in vitro reperfusion model. $\mathrm{Br} \mathrm{J}$ Pharmacol 133(6):841-848. doi:10.1038/sj.bjp.0704146

127. Suzumura A, Ito A, Yoshikawa M, Sawada M (1999) Ibudilast suppresses TNFalphaproductionbyglial cellsfunctioning mainly as type III phosphodiesterase inhibitor in the CNS. Brain Res 837(1-2):203-212

128. Mizuno T, Kurotani T, Komatsu Y, Kawanokuchi J, Kato H, MitsumaN, SuzumuraA(2004)Neuroprotectiverole of phosphodiesterase inhibitor ibudilast on neuronal cell death induced by activated microglia. Neuropharmacology 46(3):404-411. doi:10. 1016/j.neuropharm.2003.09.009

129. Fujimoto T, Sakoda S, Fujimura H, Yanagihara T(1999) Ibudilast, a phosphodiesterase inhibitor, ameliorates experimental autoimmune encephalomyelitis in Dark August rats. J Neuroimmunol 95(1-2):35-42

130. Wakita H, Tomimoto H, Akiguchi I, Lin JX, Ihara M, Ohtani R, ShibataM(2003)Ibudilast, aphosphodiesteraseinhibitor,protects against white matter damage under chronic cerebral hypoperfusion in the rat. Brain Res 992(1):53-59

131. Kagitani-Shimono K, Mohri I, Fujitani Y, Suzuki K, Ozono K, Urade Y, Taniike M (2005) Anti-inflammatory therapy by ibudilast, a phosphodiesterase inhibitor, in demyelination of twitcher, a genetic demyelination model. J Neuroinflammation 2(1):10. doi:10.1186/1742-2094-2-10

132. Rolan P, Hutchinson M, Johnson K (2009) Ibudilast: a review of its pharmacology, efficacy and safety in respiratory and neurological disease. Expert Opin Pharmacother 10(17):2897-2904. doi: $10.1517 / 14656560903426189$

133. Lobsiger CS, Cleveland DW (2007) Glial cells as intrinsic components of non-cell-autonomous neurodegenerative disease. Nat Neurosci 10(11):1355-1360. doi:10.1038/nn1988

134. Barkhof F, Hulst HE, Drulovic J, Uitdehaag BM, Matsuda K, Landin R (2010) Ibudilast in relapsing-remitting multiple sclerosis: a neuroprotectant? Neurology 74(13):1033-1040. doi:10. 1212/WNL.0b013e3181d7d651

135. Miller RG, Zhang R, Block G, Katz J, Barohn R, Kasarskis E, Forshew D, Gopalakrishnan V et al (2014) NP001 regulation of macrophage activation markers in ALS: a phase I clinical and biomarker study. Amyotroph Lateral Scler Frontotemporal Degener 15(7-8):601-609. doi:10.3109/21678421.2014.951940

136. Miller RG, Block G, Katz JS, Barohn RJ, Gopalakrishnan V, Cudkowicz M, Zhang JR, McGrath MS et al (2015) Randomized phase 2 trial of NP001-a novel immune regulator: safety and early efficacy in ALS. Neurol Neuroimmunol Neuroinflamm 2(3):e100. doi:10.1212/nxi.0000000000000100
137. Kappos L, Antel J, Comi G, Montalban X, O'Connor P, Polman CH, Haas T, Korn AA et al (2006) Oral fingolimod (FTY720) for relapsing multiple sclerosis. N Engl J Med 355(11):1124-1140. doi:10.1056/NEJMoa052643

138. Mandala S, Hajdu R, Bergstrom J, Quackenbush E, Xie J, Milligan J, Thornton R, Shei GJ et al (2002) Alteration of lymphocyte trafficking by sphingosine-1-phosphate receptor agonists. Science 296(5566):346-349. doi:10.1126/science.1070238

139. Miron VE, Schubart A, Antel JP (2008) Central nervous systemdirected effects of FTY720 (fingolimod). J Neurol Sci 274(1-2): 13-17. doi:10.1016/j.jns.2008.06.031

140. Noda H, Takeuchi H, Mizuno T, Suzumura A (2013) Fingolimod phosphate promotes the neuroprotective effects of microglia. $\mathrm{J}$ Neuroimmunol 256(1-2):13-18. doi:10.1016/j.jneuroim.2012. 12.005

141. Wei Y, Yemisci M, Kim HH, Yung LM, Shin HK, Hwang SK, Guo S, Qin Tet al (2011) Fingolimod provides long-term protection in rodent models of cerebral ischemia. Ann Neurol 69(1): 119-129. doi:10.1002/ana.22186

142. Gao F, Liu Y,Li X, Wang Y, Wei D, Jiang W (2012) Fingolimod (FTY720) inhibits neuroinflammation and attenuates spontaneous convulsions in lithium-pilocarpineinduced status epilepticus in rat model. Pharmacol Biochem Behav 103(2):187-196. doi:10.1016/ j.pbb.2012.08.025

143. Lee KD, Chow WN, Sato-Bigbee C, Graf MR, Graham RS, Colello RJ, Young HF, Mathern BE (2009) FTY720 reduces inflammation and promotes functional recovery after spinal cord injury. J Neurotrauma 26(12):2335-2344. doi:10.1089/neu.2008. 0840

144. Cipriani R, Chara JC, Rodriguez-Antiguedad A, Matute C (2015) FTY720 attenuates excitotoxicity and neuroinflammation. J Neuroinflammation 12:86. doi:10.1186/s12974-015-0308-6

145. Potenza RL, De Simone R, Armida M, Mazziotti V, Pezzola A, Popoli P, Minghetti L (2016) Fingolimod: a disease-modifier drug in a mouse model of amyotrophic lateral sclerosis. Neurotherapeutics. doi:10.1007/s13311-016-0462-2

146. DiMarco JP, O'Connor P, Cohen JA, Reder AT, Zhang-Auberson L, Tang D, Collins W, Kappos L (2014) First-dose effects of fingolimod: pooled safety data from three phase 3 studies. Mult Scler Relat Disord 3(5):629-638. doi:10.1016/j.msard.2014.05. 005

147. Khatri BO (2016) Fingolimod in the treatment of relapsingremitting multiple sclerosis: long-term experience and an update on the clinical evidence. Ther Adv Neurol Disord 9(2):130-147. doi:10.1177/1756285616628766

148. Ilzecka J, Stelmasiak Z, Dobosz B (2001) Interleukin-1beta converting enzyme/caspase-1 (ICE/caspase-1) and soluble APO1/Fas/CD 95 receptor in amyotrophic lateral sclerosis patients. Acta Neurol Scand 103(4):255-258

149. Martinon F, Mayor A, Tschopp J (2009) The inflammasomes: guardians of the body. Annu Rev Immunol 27:229-265. doi:10. 1146/annurev.immunol.021908.132715

150. Meissner F, Molawi K, Zychlinsky A (2010) Mutant superoxide dismutase 1-induced IL-1beta accelerates ALS pathogenesis. Proc Natl Acad Sci U S A 107(29):13046-13050. doi:10.1073/pnas. 1002396107

151. Maier A, Deigendesch N, Muller K, Weishaupt JH, Krannich A, Rohle R, Meissner F, Molawi K et al (2015) Interleukin-1 antagonist anakinra in amyotrophic lateral sclerosis - a pilot study. PLoS One 10(10):e0139684. doi:10.1371/journal.pone.0139684

152. Bresnihan B (2001) The safety and efficacy of interleukin-1 receptor antagonist in the treatment of rheumatoid arthritis. Semin Arthritis Rheum 30(5 Suppl 2):17-20

153. Galea J, Ogungbenro K, Hulme S, Greenhalgh A, Aarons L, Scarth S, Hutchinson P, Grainger S et al (2011) Intravenous anakinra can achieve experimentally effective concentrations in 
the central nervous system within a therapeutic time window: results of a dose-ranging study. J Cereb Blood Flow Metab 31(2):439-447. doi:10.1038/jcbfm.2010.103

154. Mizwicki MT, Fiala M, Magpantay L, Aziz N, Sayre J, Liu G, Siani A, Chan D et al (2012) Tocilizumab attenuates inflammation in ALS patients through inhibition of IL6 receptor signaling. Am J Neurodegener Dis 1(3):305-315

155. Fiala M, Mizwicki MT, Weitzman R, Magpantay L, Nishimoto N (2013) Tocilizumab infusion therapy normalizes inflammation in sporadic ALS patients. Am J Neurodegener Dis 2(2):129-139

156. Han Y, Ripley B, Serada S, Naka T, Fujimoto M (2016) Interleukin-6 deficiency does not affect motor neuron disease caused by superoxide dismutase 1 mutation. PLoS One 11(4): e0153399. doi:10.1371/journal.pone.0153399

157. Patin F, Baranek T, Vourc'h P, Nadal-Desbarats L, Goossens JF, Marouillat S, Dessein AF, Descat A et al (2016) Combined metabolomics and transcriptomics approaches to assess the IL-6 blockade as a therapeutic of ALS: deleterious alteration of lipid metabolism. Neurotherapeutics.doi:10.1007/s13311-016-0461-3

158. Khasnavis S, Jana A, Roy A, Mazumder M, Bhushan B, Wood T, Ghosh S, Watson R et al (2012) Suppression of nuclear factorkappaB activation and inflammation in microglia by physically modified saline. J Biol Chem 287(35):29529-29542. doi:10. 1074/jbc.M111.338012

159. Mondal S, Martinson JA, Ghosh S, Watson R, Pahan K (2012) Protection of Tregs, suppression of Th1 and Th17 cells, and amelioration of experimental allergic encephalomyelitis by a physically-modified saline. PLoS One 7(12):e51869. doi:10. 1371/journal.pone.0051869

160. Choi S, Yu E, Kim DS, Sugimori M, Llinas RR (2015) RNS60, a charge-stabilized nanostructure saline alters Xenopus laevis oocyte biophysical membrane properties by enhancing mitochondrial ATPproduction. Physiol Rep 3(3). doi:10.14814/phy2.12261

161. Roy A, Modi KK, Khasnavis S, Ghosh S, Watson R, Pahan K (2014) Enhancement of morphological plasticity in hippocampal neurons by a physically modified saline via phosphatidylinositol-3 kinase. PLoS One 9(7):e101883. doi:10.1371/journal.pone. 0101883

162. Modi KK, Jana A, Ghosh S, Watson R, Pahan K (2014) A physically-modified saline suppresses neuronal apoptosis, attenuates tau phosphorylation and protects memory in an animal model of Alzheimer's disease. PLoS One 9(8):e103606. doi:10.1371/ journal.pone.0103606

163. Khasnavis S, Roy A, Ghosh S, Watson R, Pahan K (2014) Protection of dopaminergic neurons in a mouse model of Parkinson's disease by a physically-modified saline containing charge-stabilized nanobubbles. J NeuroImmune Pharmacol 9(2): 218-232. doi:10.1007/s11481-013-9503-3

164. Rao VTS, Khan D, Jones RG, Nakamura DS, Kennedy TE, Cui QL, Rone MB, Healy LM et al (2016) Potential benefit of the charge-stabilized nanostructure saline RNS60 for myelin maintenance and repair. Sci Rep 6.doi:10.1038/srep30020

165. Choi S, Yu E, Rabello G, Merlo S, Zemmar A, Walton KD, Moreno H, Moreira JE et al (2014) Enhanced synaptic transmission at the squid giant synapse by artificial seawater based on physically modified saline. Front Synaptic Neurosci 6:2. doi:10. 3389/fnsyn.2014.00002

166. Berger J, Moller DE (2002) The mechanisms of action of PPARs. Annu Rev Med 53:409-435. doi:10.1146/annurev.med.53. 082901.104018

167. Daynes RA, Jones DC (2002) Emerging roles of PPARs in inflammation and immunity. Nat Rev Immunol 2(10):748-759. doi:10. 1038/nri912

168. Delerive P, Fruchart JC, Staels B (2001) Peroxisome proliferatoractivated receptors in inflammation control. J Endocrinol 169(3): 453-459
169. Devchand PR, Keller H, Peters JM, Vazquez M, Gonzalez FJ, Wahli W (1996) The PPARalpha-leukotriene B4 pathway to inflammation control. Nature 384(6604):39-43. doi:10.1038/ 384039a0

170. Heneka MT, Feinstein DL, Galea E, Gleichmann M, Wullner U, Klockgether T (1999) Peroxisome proliferator-activated receptor gamma agonists protect cerebellar granule cells from cytokineinduced apoptotic cell death by inhibition of inducible nitric oxide synthase. J Neuroimmunol 100(1-2):156-168

171. Combs CK, Johnson DE, Karlo JC, Cannady SB, Landreth GE (2000) Inflammatory mechanisms in Alzheimer's disease: inhibition of beta-amyloid-stimulated proinflammatory responses and neurotoxicity by PPARgamma agonists. J Neurosci 20(2):558567

172. Heneka MT, Klockgether T, Feinstein DL (2000) Peroxisome proliferator-activated receptor-gamma ligands reduce neuronal inducible nitric oxide synthase expression and cell death in vivo. J Neurosci 20(18):6862-6867

173. Shibata N, Kawaguchi-Niida M, Yamamoto T, Toi S, Hirano A, Kobayashi M(2008) Effects of the PPARgamma activator pioglitazone on 38 MAP kinase and IkappaBalpha in the spinal cord of a transgenic mouse model of amyotrophic lateral sclerosis. Neuropathology 28(4):387-398. doi:10.1111/j.1440-1789.2008. 00890.x

174. Schutz B, Reimann J, Dumitrescu-Ozimek L, Kappes-Horn K, Landreth GE, Schurmann B, Zimmer A, Heneka MT (2005) The oral antidiabetic pioglitazone protects from neurodegeneration and amyotrophic lateral sclerosis-like symptoms in superoxide dismutase-G93A transgenic mice. J Neurosci 25(34):7805-7812. doi:10.1523/jneurosci.2038-05.2005

175. Kiaei M, Kipiani K, Chen J, Calingasan NY, Beal MF (2005) Peroxisome proliferator-activated receptor-gamma agonist extends survival in transgenic mouse model of amyotrophic lateral sclerosis. Exp Neurol 191(2):331-336. doi:10.1016/j.expneurol. 2004.10.007

176. Dupuis L, Dengler R, Heneka MT, Meyer T, Zierz S, Kassubek J, Fischer W, Steiner F et al (2012) A randomized, double blind, placebo-controlled trial of pioglitazone in combination with riluzole in amyotrophic lateral sclerosis. PLoS One 7(6):e37885. doi:10.1371/journal.pone.0037885

177. Rothstein JD, Dykes-Hoberg M, Pardo CA, Bristol LA, Jin L, Kuncl RW, Kanai Y, Hediger MA et al (1996) Knockout of glutamate transporters reveals a major role for astroglial transport in excitotoxicity and clearance of glutamate. Neuron 16(3):675-686

178. Bezzi P, Carmignoto G, Pasti L, Vesce S, Rossi D, Rizzini BL, Pozzan T, Volterra A (1998) Prostaglandins stimulate calciumdependent glutamate release in astrocytes. Nature 391(6664): 281-285. doi:10.1038/34651

179. Yasojima K, Tourtellotte WW, McGeer EG, McGeer PL (2001) Marked increase in cyclooxygenase-2 in ALS spinal cord: implications for therapy. Neurology 57(6):952-956

180. Almer G, Teismann P, Stevic Z, Halaschek-Wiener J, Deecke L, Kostic V, Przedborski S (2002) Increased levels of the proinflammatory prostaglandin PGE2 in CSF from ALS patients. Neurology 58(8):1277-1279

181. Drachman DB, Frank K, Dykes-Hoberg M, Teismann P, Almer G, Przedborski S, Rothstein JD (2002) Cyclooxygenase 2 inhibition protects motor neurons and prolongs survival in a transgenic mouse model of ALS. Ann Neurol 52(6):771-778. doi:10.1002/ ana. 10374

182. Westerheide SD, Bosman JD, Mbadugha BN, Kawahara TL, Matsumoto G, Kim S, Gu W, Devlin JP et al (2004) Celastrols as inducers of the heat shock response and cytoprotection. J Biol Chem 279(53):56053-56060. doi:10.1074/jbc.M409267200

183. Kiaei M, Kipiani K, Petri S, Chen J, Calingasan NY, Beal MF (2005) Celastrol blocks neuronal cell death and extends life in 
transgenic mouse model of amyotrophic lateral sclerosis. Neurodegener Dis 2(5):246-254. doi:10.1159/000090364

184. Traynor BJ, Bruijn L, Conwit R, Beal F, O'Neill G, Fagan SC, Cudkowicz ME (2006) Neuroprotective agents for clinical trials in ALS: a systematic assessment. Neurology 67(1):20-27. doi:10. 1212/01.wnl.0000223353.34006.54

185. Stella N (2009) Endocannabinoid signaling in microglial cells. Neuropharmacology 56(Suppl 1):244-253. doi:10.1016/j. neuropharm.2008.07.037

186. Quartilho A, Mata HP, Ibrahim MM, Vanderah TW, Porreca F, Makriyannis A, Malan TP Jr (2003) Inhibition of inflammatory hyperalgesia by activation of peripheral CB2 cannabinoid receptors. Anesthesiology 99(4):955-960

187. Kim K, Moore DH, Makriyannis A, Abood ME (2006) AM1241, a cannabinoid CB2 receptor selective compound, delays disease progression in a mouse model of amyotrophic lateral sclerosis. Eur $\mathrm{J}$ Pharmacol 542(1-3):100-105. doi:10.1016/j.ejphar.2006.05.025

188. Yiangou Y, Facer P, Durrenberger P, Chessell IP, Naylor A, Bountra C, Banati RR, Anand P (2006) COX-2, CB2 and $\mathrm{P} 2 \mathrm{X} 7$-immunoreactivities are increased in activated microglial cells/macrophages of multiple sclerosis and amyotrophic lateral sclerosis spinal cord. BMC Neurol 6:12. doi:10.1186/14712377-6-12

189. Shoemaker JL, Seely KA, Reed RL, Crow JP, Prather PL (2007) The CB2 cannabinoid agonist AM-1241 prolongs survival in a transgenic mouse model of amyotrophic lateral sclerosis when initiated at symptom onset. J Neurochem 101(1):87-98. doi:10. 1111/j.1471-4159.2006.04346.x

190. Yao BB, Mukherjee S, Fan Y, Garrison TR, Daza AV, Grayson GK, Hooker BA, Dart MJ et al (2006) In vitro pharmacological characterization of AM1241: a protean agonist at the cannabinoid CB2 receptor? Br J Pharmacol 149(2):145-154. doi:10.1038/sj. bjp.0706838

191. Chung YH, Hong JJ, Shin CM, Joo KM, Kim MJ, Cha CI (2003) Immunohistochemical study on the distribution of homocysteine in the central nervous system of transgenic mice expressing a human Cu/Zn SOD mutation. Brain Res 967(1-2):226-234

192. Lipton SA, Kim WK, Choi YB, Kumar S, D'Emilia DM, Rayudu PV, Arnelle DR, Stamler JS (1997) Neurotoxicity associated with dual actions of homocysteine at the N-methyl-D-aspartate receptor. Proc Natl Acad Sci U S A 94(11):5923-5928

193. Zhang X, Chen S, Li L, Wang Q, Le W (2008) Folic acid protects motor neurons against the increased homocysteine, inflammation and a poptosis in SOD1 G93A tran sgenic mice. Neuropharmacology 54(7):1112-1119. doi:10.1016/j. neuropharm.2008.02.020

194. Gravel M, Beland LC, Soucy G, Abdelhamid E, Rahimian R, Gravel C, Kriz J (2016) IL-10 controls early microglial phenotypes and disease onset in ALS caused by misfolded superoxide dismutase 1. J Neurosci 36(3):1031-1048. doi:10.1523/jneurosci. 0854-15.2016

195. Butovsky O, Ziv Y, Schwartz A, Landa G, Talpalar AE, Pluchino S, Martino G, Schwartz M (2006) Microglia activated by IL-4 or IFN-gamma differentially induce neurogenesis and oligodendrogenesis from adult stem/progenitor cells. Mol Cell Neurosci31(1):149-160. doi:10.1016/j.mcn.2005.10.006

196. Holmoy T (2008) T cells in amyotrophic lateral sclerosis. Eur J Neurol 15(4):360-366. doi:10.1111/j.1468-1331.2008.02065.x

197. Zhang DE, Hetherington CJ, Chen HM, Tenen DG (1994) The macrophage transcription factor PU.1 directs tissue-specific expression of the macrophage colony-stimulating factor receptor. Mol Cell Biol 14(1):373-381

198. Gomez-Nicola D, Perry VH (2015) Microglial dynamics and role in the healthy and diseased brain: a paradigm of functional plasticity. Neuroscientist 21(2):169 - 184. doi: 10 .1177/ 1073858414530512
199. Yamamoto S, Nakajima K, Kohsaka S (2010) Macrophage-colony stimulating factor as an inducer of microglial proliferation in axotomized rat facial nucleus. J Neurochem 115(4):1057-1067. doi:10.1111/j.1471-4159.2010.06996.x

200. Gomez-Nicola D, Fransen NL, Suzzi S, Perry VH (2013) Regulation of microglial proliferation during chronic neurodegeneration. J Neurosci 33(6):2481-2493. doi:10.1523/jneurosci. 4440-12.2013

201. Crespo O, Kang SC, Daneman R, Lindstrom TM, Ho PP, Sobel RA, Steinman L, Robinson WH (2011) Tyrosine kinase inhibitors ameliorate autoimmune encephalomyelitis in a mouse model of multiple sclerosis. J Clin Immunol 31(6):1010-1020. doi:10.1007/ s10875-011-9579-6

202. Olmos-Alonso A, Schetters ST, Sri S, Askew K, Mancuso R, Vargas-Caballero M, Holscher C, Perry VH et al (2016) Pharmacological targeting of CSF1R inhibits microglial proliferation and prevents the progression of Alzheimer's-like pathology. Brain 139(Pt 3):891-907. doi:10.1093/brain/awv379

203. Martinez-Muriana A, Mancuso R, Francos-Quijorna I, OlmosAlonso A, Osta R, Perry VH, Navarro X, Gomez-Nicola D et al (2016) CSF1R blockade slows the progression of amyotrophic lateral sclerosis by reducing microgliosis and invasion of macrophages into peripheral nerves. Sci Rep 6:25663. doi:10.1038/ srep25663

204. Luo J, Elwood F, Britschgi M, Villeda S, Zhang H, Ding Z, Zhu L, Alabsi H et al (2013) Colony-stimulating factor 1 receptor (CSF1R) signaling in injured neurons facilitates protection and survival. J Exp Med 210(1):157-172. doi:10.1084/jem. 20120412

205. Freischmidt A, Wieland T, Richter B, Ruf W, Schaeffer V, Muller K, Marroquin N, Nordin F et al (2015) Haploinsufficiency of TBK1 causes familial ALS and fronto-temporal dementia. Nat Neurosci 18(5):631-636. doi:10.1038/nn.4000

206. Ahmad L, Zhang SY, Casanova JL, Sancho-Shimizu V (2016) Human TBK1: a gatekeeper of neuroinflammation. Trends Mol Med 22(6):511-527. doi:10.1016/j.molmed.2016.04.006

207. Lim HK, Seppanen M, Hautala T, Ciancanelli MJ, Itan Y,Lafaille FG, Dell W, Lorenzo L et al (2014) TLR3 deficiency in herpes simplex encephalitis: high allelic heterogeneity and recurrence risk. Neurology 83(21):1888-1897. doi:10.1212/wnl. 0000000000000999

208. Moore AS, Holzbaur EL (2016) Dynamic recruitment and activation of ALS-associated TBK1 with its target optineurin are required for efficient mitophagy. Proc Natl Acad Sci U S A 113(24):E3349-E3358. doi:10.1073/pnas.1523810113

209. Ito Y, Ofengeim D, Najafov A, Das S, Saberi S, Li Y, Hitomi J, Zhu H et al (2016) RIPK1 mediates axonal degeneration by promoting inflammation and necroptosis in ALS. Science 353(6299): 603-608. doi:10.1126/science.aaf6803

210. Deitch JS, Alexander GM, Bensinger A, Yang S, Jiang JT, Heiman-Patterson TD (2014) Phenotype of transgenic mice carrying a very low copy number of the mutant human G93A superoxide dismutase-1 gene associated with amyotrophic lateral sclerosis.PLoS One 9(6):e99879. doi:10.1371/journal.pone.0099879

211. Gurney ME (1997) The use of transgenic mouse models of amyotrophic lateral sclerosis in preclinical drug studies. J Neurol Sci 152(Suppl 1):S67-S73

212. Matsumoto A, Okada Y, Nakamichi M, Nakamura M, Toyama Y, Sobue G, Nagai M, Aoki M et al (2006) Disease progression of human SOD1 (G93A) transgenic ALS model rats. J Neurosci Res 83(1):119-133. doi:10.1002/jnr.20708

213. Heiman-Patterson TD, Sher RB, Blankenhorn EA, Alexander G, Deitch JS, Kunst CB, Maragakis N, Cox G (2011) Effect of genetic background on phenotype variability in transgenic mouse models of amyotrophic lateral sclerosis: a window of opportunity in the search for genetic modifiers. AmyotrophLateral Scler 12(2): 79-86. doi:10.3109/17482968.2010.550626 